\title{
Lotus japonicus NF-YA1 Plays an Essential Role During Nodule Differentiation and Targets Members of the SHI/STY Gene Family
}

\author{
Md Shakhawat Hossain, ${ }^{1}$ Arina Shrestha, ${ }^{1,2}$ Sihui Zhong, ${ }^{1}$ Mandana Miri, ${ }^{1,2}$ Ryan S. Austin, ${ }^{1,2}$ \\ Shusei Sato, ${ }^{3}$ Loretta Ross, ${ }^{1}$ Terry Huebert, ${ }^{1}$ Alexandre Tromas, ${ }^{1}$ Ivone Torres-Jerez, ${ }^{4}$ Yuhong Tang, ${ }^{4}$ \\ Michael Udvardi, ${ }^{4}$ Jeremy D. Murray, ${ }^{4}$ and Krzysztof Szczyglowski ${ }^{1,2}$ \\ ${ }^{1}$ Agriculture and Agri-Food Canada, London Research and Development Centre, London, Ontario, N5V 4T3 Canada; \\ ${ }^{2}$ Department of Biology, University of Western Ontario, London, Ontario, N6A 5B7 Canada; ${ }^{3}$ Graduate School of Life Sciences, \\ Tohoku University, 2-1-1 Katahira, Sendai, 980-8577, Japan; and ${ }^{4}$ Plant Biology Division, The Samuel Roberts Noble \\ Foundation, Ardmore, Oklahoma, U.S.A.
}

Accepted 16 November 2016.

\begin{abstract}
Legume plants engage in intimate relationships with rhizobial bacteria to form nitrogen-fixing nodules, root-derived organs that accommodate the microsymbiont. Members of the Nuclear Factor $\mathrm{Y}(\mathrm{NF}-\mathrm{Y})$ gene family, which have undergone significant expansion and functional diversification during plant evolution, are essential for this symbiotic liaison. Acting in a partially redundant manner, NF-Y proteins were shown, previously, to regulate bacterial infection, including selection of a superior rhizobial strain, and to mediate nodule structure formation. However, the exact mechanism by which these transcriptional factors exert their symbiotic functions has remained elusive. By carrying out detailed functional analyses of Lotus japonicus mutants, we demonstrate that $L j N F-Y A 1$ becomes indispensable downstream from the initial cortical cell divisions but prior to nodule differentiation, including cell enlargement and vascular bundle formation. Three affiliates of the SHORT INTERNODES/STYLISH transcription factor gene family, called STY1, STY2, and STY3, are demonstrated to be among likely direct targets of LjNF-YA1, and our results point to their involvement in nodule formation.
\end{abstract}

Transcriptional reprograming, one of the key drivers of cellular specification (Smith et al. 2016), is integral to root-nodule

M. S. Hossain, A. Shrestha, and S. Zhong contributed equally to this work.

Microarray data were deposited in ArrayExpress under accession number E-MTAB-4970.

Current address for M. S. Hossain: Division of Plant Sciences, National Center for Soybean Biotechnology, University of Missouri, Columbia, MO 65211, U.S.A.

Current address for J. D. Murray: John Innes Centre, Norwich Research Park, Colney, Norwich NR4 7UH, U.K.

Current address for A. Tromas: Centro de Ciencias Genómicas; Universidad Nacional Autónoma de México, Cuernavaca, Morelos 62210, Mexico.

Corresponding author: K. Szczyglowski;

E-mail: Krzysztof.Szczyglowski@agr.gc.ca

*The $\boldsymbol{e}$-Xtra logo stands for "electronic extra" and indicates that eight supplementary figures and two supplementary tables are published online.

(c) 2016 The American Phytopathological Society development (Høgslund et al. 2009; Moreau et al. 2011; Soyano and Hayashi 2014). Nodules are lateral organs that differentiate from root cortical and pericycle cells following the symbiotic signaling that occurs between leguminous plants and nitrogenfixing rhizobial bacteria (Desbrosses and Stougaard 2011; Oldroyd et al. 2011; Suzaki et al. 2015). Several transcription factors have been shown to play an essential role during nodule differentiation (Soyano and Hayashi 2014). Among them, members of the CCAAT-box binding transcriptional factor family, known as Heme Activator or Nuclear Factor Y (NF-Y) proteins, have emerged as important plant regulators of early nodulation events (Battaglia et al. 2014; Combier et al. 2006, 2008; Laloum et al. 2013, 2014; Laporte et al. 2014; Soyano et al. 2013; Zanetti et al. 2010).

NF-Ys are heterotrimeric protein complexes composed of the NF-YA, NF-YB, and NF-YC subunits (Dolfini et al. 2012; Laloum et al. 2013; Mantovani 1999). In animals, NF-Ys are known to regulate genes associated with the cell-cycle progression and those related to various diseases (Dolfini et al. 2016; Ly et al. 2013). Unlike animals and fungi, plants have evolved multiple copies of genes encoding each of the three NF-Y subunits, for which both ubiquitous and more specialized expression patterns are known (Laloum et al. 2013; Petroni et al. 2013; Siefers et al. 2009). Plants in the legume (Leguminosae) family have co-opted some of these genes, such as Medicago truncatula NF-YAl (MtNF-YAl) and MtNF-YA2 (Baudin et al. 2015; Combier et al. 2006, 2008; Laloum et al. 2014), Phaseolus vulgaris NF-YCl (PvNF-YC1) (Battaglia et al. 2014; Zanetti et al. 2010), and Lotus japonicus NF-YA1 (LjNF-YA1) and LjNF-YB1 (Soyano et al. 2013), to perform specialized functions during the development of nitrogenfixing root-nodule symbiosis. A role for soybean (Glycine max) $G m N F-Y A l a$ and $G m N F-Y A l b$ as positive regulators of arbuscular mycorrhizae (AM) (Corradi and Bonfante 2012; Parniske 2008) and as potential targets of the autoregulatory mechanism that restricts the extent of root colonization by AM fungi has also been documented (Schaarschmidt et al. 2013). Together, these findings demonstrate the importance of NF-Y transcription factors in mediating the two major classes of plant-microbe endosymbiosis.

The establishment of nitrogen-fixing root nodules involves two spatially and temporally coordinated processes and NF-Ys are important for both (Combier et al. 2006, 2008; Laporte et al. 2014; Zanetti et al. 2010). At the root surface, symbiotic colonization commences with a mutual recognition (Kawaharada et al. 2015; Lerouge et al. 1990) that initiates the formation of 
root hair infection threads (ITs), plant plasma membranederived transcellular tunnels that guide rhizobia inside the root (Fournier et al. 2015; Miri et al. 2016). In the subtending inner root, presumed cell nonautonomous root epidermis to cortex signaling that precedes bacterial entry activates mitotic cell divisions for nodule primordia (NP) formation (Held et al. 2014; Madsen et al. 2010). Both of these cellular events commence as a result of a compatible interaction between symbionts, wherein bacterially-encoded lipochito-oligosaccharide signaling molecules, known as nodulation factors (NF), are perceived by the host plant NF receptor complex at the root epidermis (Arrighi et al. 2006; Broghammer et al. 2012; Limpens et al. 2003; Madsen et al. 2003; Radutoiu et al. 2003, 2007). This triggers the NFdependent root response pathway (Geurts et al. 2016), with rapid calcium $\left(\mathrm{Ca}^{2+}\right)$ influx and the perinuclear fluctuation of $\mathrm{Ca}^{2+}$ concentrations in the root epidermis, known as $\mathrm{Ca}^{2+}$ spiking, among the earliest cellular responses (Charpentier et al. 2016; Morieri et al. 2013; Oldroyd and Downie 2006). $\mathrm{Ca}^{2+}$ and calmodulin-dependent receptor kinase (CCaMK) transduces these $\mathrm{Ca}^{2+}$ signals to downstream effectors (Lévy et al. 2004; Mitra et al. 2004; Tirichine et al. 2006b), including a nuclear coiled-coil protein, CYCLOPS. CYCLOPS, the direct phosphorylation target of CCaMK (Singh et al. 2014; Yano et al. 2008), participates in the NF/CCaMK-dependent transcriptional reprograming and its artificial activation in L. japonicus is sufficient to stimulate formation of empty root-nodule structures in the absence of any external stimulus, including rhizobia and NF (Limpens and Bisseling 2014; Singh et al. 2014). The regulator NODULE INCEPTION (NIN), a RWP-RK domain-containing protein, which is essential for both rhizobial infection and nodule organogenesis (Marsh et al. 2007; Schauser et al. 1999; Vernié et al. 2015), partakes in the CYCLOPS-dependent specification. CYCLOPS regulates expression of NIN (Singh et al. 2014) and, in L. japonicus, NIN was shown to directly activate $L j N F-Y A 1$ and $L j N F-Y B 1$, which is required for normal nodule organogenesis (Soyano et al. 2013).

$M t N F-Y A 1$ was the first nodule-specific $N F-Y$ gene to be identified and functionally characterized in the context of indeterminate, meristem-containing nodule development in Medicago truncatula (Combier et al. 2006, 2008). It was shown to be necessary for the regulation of cell proliferation and proper formation of nodule meristem, where it is expressed (Combier et al. 2006, 2008; Xiao et al. 2014). Subsequent research highlighted an additional role for MtNF-YAl in the root epidermis, in which it acts partially redundantly with $M t N F-Y A 2$ to control bacterial infection (Laloum et al. 2014; Laporte et al. 2014).

Expression of MtNF-YAl is regulated at both transcriptional and posttranscriptional levels, with the latter involving miR169 and an unusual, trans-acting peptide derived from the upstream open reading frame (uORF) of an alternatively spliced $M t N F$ YA1 mRNA (Combier et al. 2008). These posttranscriptional mechanisms are thought to account for the tight spatial and temporal regulation of the $M t N F-Y A l$ gene expression domains during indeterminate nodule development (Combier et al. 2006, 2008). RNA interference (RNAi)-mediated downregulation of the MtNF-YAl gene expression resulted in attenuation of nodule growth, a defect mimicked by constitutive overexpression of miR169 (Combier et al. 2006). This negative effect was further accentuated in the Mtnf-yal-1 loss-of-function mutant, in which the impairment in the rhizobial infection also becomes apparent. Mtnf-yal-1 forms ITs with cell walls that are half the thickness of those in wild type, which likely accounts for the observed instability of the infection process in the mutant (Laporte et al. 2014). The symbiotic defects are even more severe when $M t N F-Y A 1$ and $M t-N F-Y A 2$ are simultaneously impaired, which leads to few or no nodules and a significant, early block in infection (Laloum et al. 2014).
NF-Ys are also pertinent during the development of determinate, meristem-deprived nodules, including the apparent participation of $P v N F-Y C l$ in a mechanism by which common bean selects for a more efficient symbiotic partner (Zanetti et al. 2010). Downregulation of PvNF-YCl through RNAi impedes nodule development and leads to defects in the infection process (Zanetti et al. 2010). Similarly, downregulation of LjNF-YAl in hairy roots was shown to significantly reduce nodule formation events, with the majority of composite plants displaying a nonnodulating phenotype, even though the IT formation was apparently not affected (Soyano et al. 2013). The presence of the LjNF-YA1 RNAi construct also prevents spontaneous nodule formation caused by a gain-of-function $C C a M K$ allele in the absence of rhizobia (Soyano et al. 2013). However, it remains unclear what specific mechanism is regulated by $N F-Y s$ during determinate nodule development and whether this is equivalent to the function of MtNF-Ys in indeterminate nodules.

By performing detailed analyses of four independent $L$. japonicus mutant lines, we demonstrate here that $L j N F-Y A 1$ is not required for IT formation and becomes essential only downstream from the initial cell divisions for NP formation. Its function during determinate nodule development in $L$. japonicus can be fully substituted by $M t N F-Y A 1$. Using transcriptomic data, we have defined several potential downstream targets for the LjNF-YA1-dependent regulation, including three members of the SHISTY gene family.

\section{RESULTS}

Identification of $L$. japonicus $\boldsymbol{n} \boldsymbol{f}$-yal mutants.

A screen for suppressors of the L. japonicus harl-1 hypernodulation phenotype (Murray et al. 2006) identified two allelic lines, harl-1 nf-yal-1 and harl-1 nf-yal-2, each carrying a secondary mutation at the LjNF-YAI locus. In contrast to the parental harl-1 line, which, at 21 days after inoculation (dai) with Mesorhizobium loti, showed the typical, short and hypernodulated root phenotype (Wopereis et al. 2000), both harl-1 nf-yal-1 and harl-1 nf-yal-2 had longer roots with many small nodules (Fig. 1A). A closer examination of the double mutant symbiotic phenotypes 10 dai showed that $M$. loti was able to readily penetrate roots; however, these root colonization events were apparently met with a limited cortical response, resulting in the presence of a large number of NP and small nodule bumps (Fig. 1B). At 21 dai, NP formation was enhanced in harl-1 nf-yal-1 and harl-1 nf-yal-2, such that they significantly outnumbered the corresponding events in harl-1 (Fig. 1C). By contrast, the number of mature nodules was significantly diminished in harl-1 nf-yal-1 and harl-1 nf-yal-2 as compared with harl-1 and many of them were small in size (Fig. 1C).

Sequencing of the LjNF-YAl gene, selected as a candidate locus based on the map-based cloning experiment, showed the presence of the $\mathrm{G}_{2418}$ to A splice-site mutation and the $\mathrm{G}_{3309}$ to A substitution that define the $n f-y a 1-1$ and $n f-y a 1-2$ mutant alleles, respectively (Supplementary Figs. S1 and S2). F1 plants derived from four independent allelic crosses between the corresponding $n f-y a l-1$ and $n f-y a l-2$ single mutants (carrying the wild-type HARl allele), displayed the same mutant nodulation phenotype. Together with the phenotypic complementation of the $n f-y a 1-2$ nodulation defect with the wild-type LjNF-YAl gene and also with MtNF-YAl (Supplementary Fig. S3), these data provided unambiguous proof for the causative nature of $n f-y a l-1$ and $n f-y a l-2$ alleles for the observed mutant symbiotic phenotypes.

\section{The NF-YAI gene.}

The L. japonicus genome contains a family of at least nine genes that are predicted to encode $\mathrm{LjNF}$-YA proteins, named here as LjNF-YA1 to LjNF-YA9 (Supplementary Fig. S4). The LjNF-YAl gene is composed of eight exons encoding a 
1,618-nucleotide (nt)-long LjNF-YA1 mRNA, including 5' and $3^{\prime}$ untranslated regions (UTRs). The adenine residue (A) in the predicted ATG initiation codon is located in the fourth exon, 247 nts downstream from the mRNA 5' end. This begins the 996-nt-long ORF for the conceptual LjNF-YA1 protein. The first and second exons of the LjNF-YAl gene encompass a predicted uORF of $93 \mathrm{nt}$, which is in-frame with the main ORF. The 376-nt-long 3' UTR contains the 5'-AAGGCAACTC ATTCTTGGCTA-3' sequence, a predicted target of miR169.

The LjNF-YA1 protein (GenBank accession number AB378633) has a high primary sequence homology with NF-YAs from different plant species, including Glycine max NF-YA10 (GenBank accession number KHN43704, 77\% identity and $84 \%$ similarity), Medicago truncatula NF-YA1 (GenBank accession number ABP68866.1, 76\% identity and 83\% similarity), and Arabidopsis thaliana NF-YA10 (GenBank accession number NP_196269, 42\% identity and 51\% similarity). All share a highly conserved CCAAT-binding transcription factor domain (Laloum et al. 2013). This domain includes subunit interaction (SI) and DNA binding (DB) regions that are highly conserved between NF-YA proteins in different species (Fig. 2) (Laloum et al. 2013). Both $n f-y a l-1$ and $n f-y a 1-2$ mutations are predicted to alter the NF-YA domain, leading either to a deletion of a portion of the SI region or a substitution of an invariant glycine residue $\left(\mathrm{G}_{213}\right)$ to aspartic acid (D) within the DB region of the LjNF-YA1 protein, respectively (Fig. 2).

Additional $\boldsymbol{n f}$-yal alleles.

Both harl-1 nf-yal-1 and harl-1 nf-yal-2 were backcrossed to wild-type L. japonicus 'Gifu' and the corresponding $n f-y a l-1$ and nf-yal-2 mutants carrying the wild-type $H A R l$ gene were selected. The presence of either of these $n f$-yal alleles, each characterized by a single nucleotide substitution, leads to similar, mutant nodulation phenotypes, and $n f-y a 1-2$ was chosen for subsequent detailed analyses. To assess whether a null mutation at the LjNF-YAl locus would potentiate the symbiotic defect, additional alleles called $n f-y a 1-3$ and $n f-y a 1-4$, were selected from the L. japonicus LORE1 retrotransposon resource (Fukai et al. 2012; Małolepszy et al. 2016; Urbański et al. 2012). In nf-yal-3, LORE1 is inserted immediately after the ATG initiation codon of the main ORF, while $n f-y a 1-4$ carries the LORE1 insertion in the same exon, $104 \mathrm{bp}$ downstream from the ATG. The presence of the 5.041-kb LORE1 sequence at the beginning of the $L j N F-Y A l$ coding region introduces multiple premature, translational stop codons. As the entire LORE1 sequence remains and is transcribed within the corresponding $n f-y a l-3$ and $n f-y a l-4$ mRNAs, we considered these as strong or loss-of-function alleles.

Comparative phenotypic analysis of $n f-y a l-2$ with $n f-y a l-3$ and nf-yal-4 LORE1 insertion lines showed that they all have similar symbiotic defects. When scored 7 dai, all three mutants developed NP (i.e., foci of cortical cell divisions), but mature nodules were rarely formed (e.g., on average $0.26 \pm 0.23$ nodules per $n f$-yal-2 plant). By contrast, the wild-type control developed several nodules at this early timepoint (Fig. 3A). At 21 dai, the number of NP was significantly higher and the proportion of mature nodules was significantly smaller in $n f$-yal mutants as compared with wild type (Fig. 3B). As such, the single mutants had nearly double the number of early primordia compared with wild type (Fig. 3B). Importantly, at 7 dai, all three $n f$-yal mutants had a wild-type number of epidermal ITs

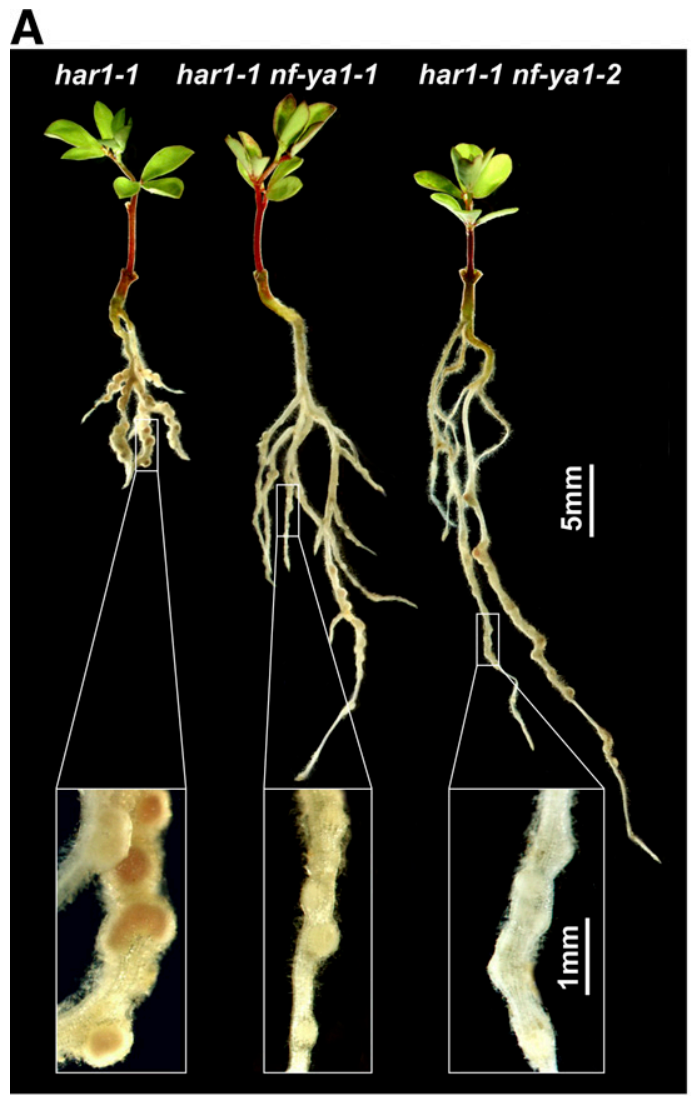

B
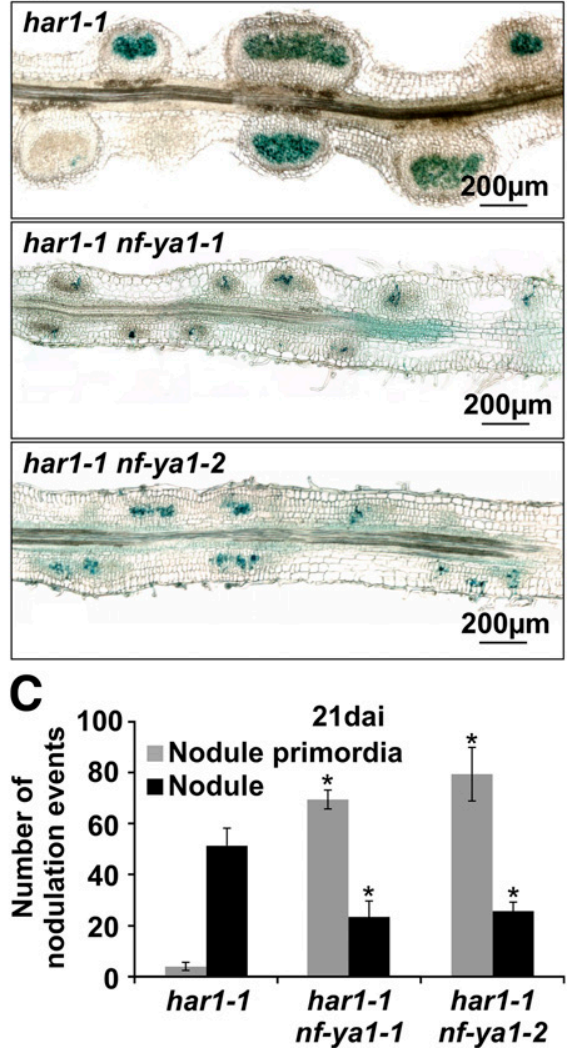

Fig. 1. Plant phenotypes. A, The harl-1 parental line and two independent, suppressor lines, harl-1 nf-yal-1 and harl-1 nf-yal-2, are shown. Plants were photographed 21 days after inoculation (dai) with Mesorhizobium loti. Note differences in the root length and nodule development (insets show more details). B, Longitudinal sections through Lotus japonicus har1-1, harl-1 nf-yal-1, and harl-1 nf-yal-2 roots that were stained for $\beta$-galactosidase activity 10 dai with M. loti NZP2235 carrying the hemA:LacZ reporter fusion (darker regions within nodules and nodule primordia indicate presence of bacteria). $\mathbf{C}$, Scores of various nodulation events 21 dai. Ten individuals were scored for each genotype and averages $\pm 95 \%$ confidence intervals are given. Asterisks $\left(^{*}\right)$ indicate values that are significantly different (Student's $t$ test, $P \leq 0.05$ ) from the corresponding harl-1 parental line. 
(eITs) (Fig. 4C). These eITs were observed to descend into the subtending root cortex (Fig. 3D), leading to NP events that, although more numerous, were seemingly wild type in appearance (Fig. 3E).

Taken together, these observations support and extend previously published data by showing that deleterious mutations at the LjNF-YAl locus restrict symbiotic development in L. japonicus downstream from the initial cell divisions by impacting the cortical program for nodule formation. This was further evaluated by performing detailed analyses of $L j N F-Y A I$ gene expression and also by examining the effect of $n f-y a l$ mutant alleles on the symbiotic development in the context of gain- and loss-of-function alleles of the L. japonicus Lhkl cytokinin receptor gene.
Expression of $\mathrm{LJNF}-\mathrm{YA} I$ associates with nodule development.

According to the L. japonicus gene expression atlas, $L j N F$ YAl is the only member of the L. japonicus NF-YA gene family that displays a strictly nodule-specific expression pattern (Verdier et al. 2013). Indeed, the NF-YAl mRNA can be detected in $M$. loti-inoculated roots but not in any other $L$. japonicus tissues tested. It rapidly accumulates within the first 2 dai, to reach the highest steady-state level at 7 dai. The NF-YAI mRNA is also detectable at 12 dai and in mature nodules, although at a comparatively lower level (Supplementary Fig. S5A and B). When examined at various stages following $M$. loti inoculation, only a single species of the LjNF-YAl mRNA could be detected in L. japonicus roots and nodules, indicating lack of

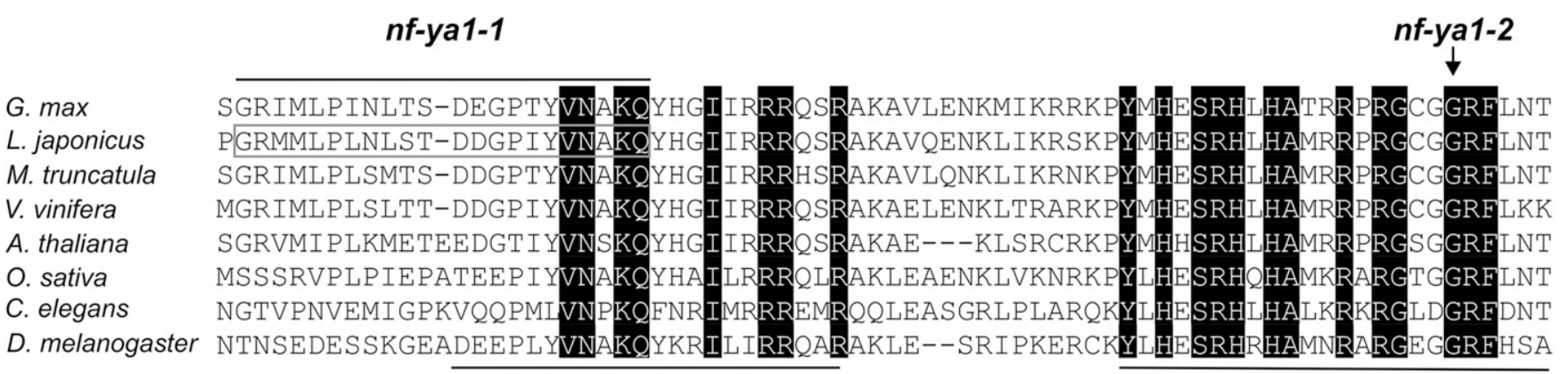

Subunit interaction

DNA binding

Fig. 2. nf-yal-1 and nf-yal-2 mutations affect conserved domains of the NF-YA1 protein. Alignment of NF-YA protein sequences encompassing the predicted subunit interaction (SI) and DNA-binding (DB) domains from different species. Only invariant amino acid residues are highlighted. The $n f$-yal-1 mutation imposes mis-splicing 66 nucleotides downstream from the predicted intron 6-exon 7 junction. As a result, 22 amino acids, including invariant VN and KQ residues within the SI domain, are deleted (as marked by boxed sequence in the Lotus japonicus NF-YA1). Note that this leaves the downstream sequence intact and preserves the remainder of the wild-type open reading frame. $n f$-yal-2 leads to substitution of an invariant glycine (G) residue to aspartic acid (D) within the predicted DB domain (arrow). The following protein sequences were used for this alignment: Glycine max (accession number XP_003519110.1), L. japonicus (BAG50060.1), Medicago truncatula (XP_003590326), Vitis venifera (XP_002263793.1), Arabidopsis thaliana (NP_196269), Oryza sativa (CAA71844.1), Caenorhabditis elegans (NP_509999.1), and Drosophila melanogaster (NP_648313.1).
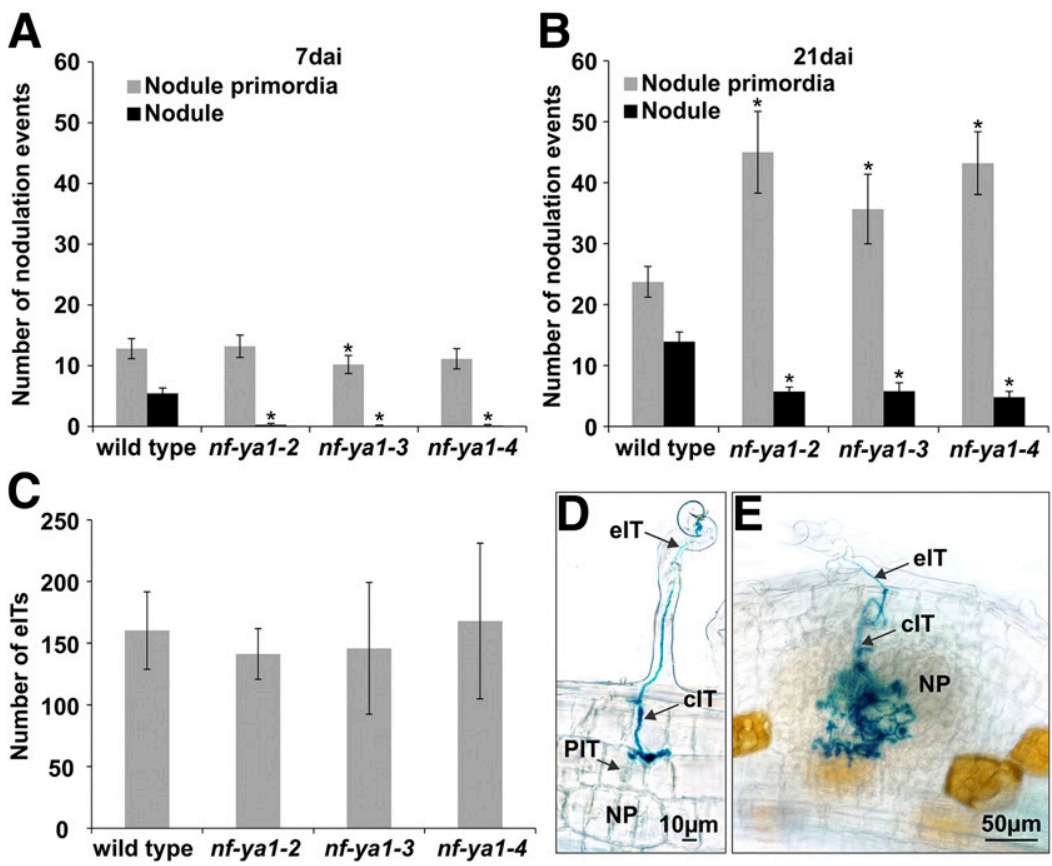

Fig. 3. $n f$-yal mutations affect the cortical program for nodule formation. A, and $\mathbf{B}$, Scores of nodulation events in wild type and $n f$-yal single mutant lines 7 and 21 days after inoculation (dai) with Mesorhizobium loti. Given the abundance of nodule primordia, roots were evaluated under higher (20x) magnification to capture even the smallest nodulation event, such as a single layer of dividing cortical cells. Ten to 15 individuals were scored for each genotype and averages $\pm 95 \%$ confidence intervals are given. Asterisks (*) indicate values that are significantly different (Student's $t$ test, $P \leq 0.05$ ) from the wild-type control. C, Number of epidermal infection threads (eITs) as formed by a given genotype at 7 dai. D, A representative eIT formed on an $n f$-yal-2 root. The eIT has successfully migrated to become a cortical IT (cIT), while descending toward an early nodule primodium (NP). PIT $=$ a preinfection thread that marks one possible route for further progression of the cIT. E, A typical nodule primordium formed by the $n f-y a l-2$ mutant having a wild-type appearance. 
alternative splicing for this mRNA under the conditions tested (Supplementary Fig. S6).

Histochemical localization indicated that the $L j N F-Y A 1$ promoter activity $\left(L j N F-Y A 1_{P r o}: G U S\right)$ associates with the earliest stages of symbiosis, including the initial cortical cell divisions for NP formation (Fig. 4A and B). The LjNF-YA1 Pro: $G U S$ activity was also detected in the root epidermis, including root hairs (Fig. 4C); however, this was rather intermittent and not

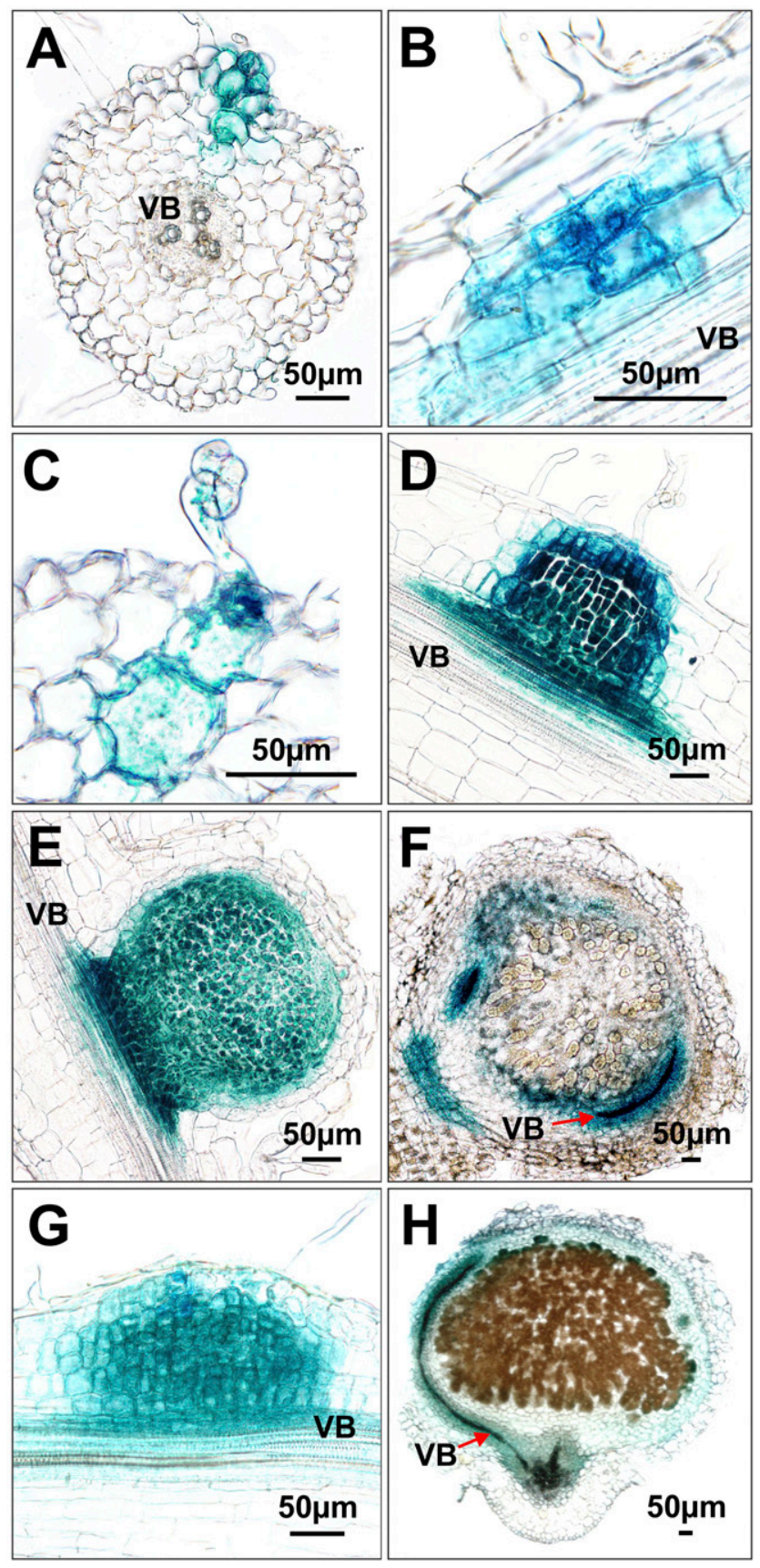

Fig. 4. Activity of the Lotus japonicus and Medicago truncatula NF-YAI promoters during L. japonicus nodule development. A to F, Fully transgenic $L$. japonicus plants showing the $L$. japonicus $N F-Y A 1_{P r o}$ :GUS reporter activity as associated with the progressive stages in nodule development. With the exception of panel F, all panels reflect approximately $35-\mu \mathrm{m}$ thick sections of previously stained specimens. Note that, in panel $\mathrm{F}$, the corresponding nodule was sectioned prior to staining for the $\beta$-glucuronidase activity. $\mathbf{G}$ and $\mathbf{H}$, Sections of a nodule primordium and a fully developed nodule, respectively, from transgenic hairy roots formed on $L$. japonicus wild-type shoots and carrying the Medicago truncatula MtNF-YA1 ${ }_{P r o}$ : GUS reporter. All images represent specimens collected at either 14 (A to F) or 21 days after inoculation $(\mathrm{G}$ and $\mathrm{H})$ with Mesorhizobium loti. $\mathrm{VB}=$ vascular bundles. always associated with eITs. Developmentally more advanced NP showed a uniform $\beta$-glucuronidase (GUS) activity in all cell types, including the root pericycle (Fig. 4D and E). With further progression in development, $L j N F-Y A 1_{P r o}: G U S$ activity gradually became restricted, eventually to be entirely confined to the nodule vasculature and vascular parenchyma in fully mature nodules (Figs. 4F and 8C). Interestingly, in M. loti-inoculated transgenic hairy roots formed on wild-type L. japonicus shoots, the Medicago truncatula $N F-Y A 1$ promoter conferred a pattern of expression that was very similar to the $L j N F-Y A l$ promoter (Fig. $4 \mathrm{G}$ and $\mathrm{H}$ ). This is consistent with the fact that the MtNF-YAl gene is able to complement the symbiotic defect of the L. japonicus nf-yal-2 mutant by restoring the wild-type nodulation phenotype.

\section{Expression of $\mathrm{NF}-\mathrm{YAI}$ is controlled by cytokinin.}

In L. japonicus, expression of LjNF-YAl is regulated by NIN (Soyano et al. 2013) and both genes respond to exogenous cytokinin (Heckmann et al. 2011; Murray et al. 2007). This is consistent with the observation that, at $50 \mathrm{nM}$, exogenous cytokinin induced the expression of $L j N F-Y A 1$ in uninoculated $L$. japonicus roots and, within the first $6 \mathrm{~h}$ of treatment, this response was both Lhkl- and NIN-dependent. The LjNF-YAI mRNA was also detectable in uninoculated roots of a $L$. japonicus mutant carrying the $s n f 2$ gain-of-function allele of the LHK1 cytokinin receptor gene but not in corresponding wild-type roots, further supporting a regulatory role for cytokinin (Supplementary Fig. 7A and B). Moreover, like NIN, the LjNF-YAl expression domain was enlarged in the $l h k l-1$ mutant. In the wild-type background, at 7 dai, the $L_{j N I N}$ Pro:GUS and $L j N F-Y A 1_{P r o}: G U S$ reporters showed punctuated activity patterns, reflecting a tight association with developing nodules. By contrast, their expression domains were extended in the lhkl-1 mutant (Supplementary Fig. 8A and B). As evidenced by the intense staining, the LjNF$Y A 1_{P r o}: G U S$ activity appeared also to be more emphasized in the lhkl-1 root epidermis, which constituted another departure from its expression pattern in wild type. Given these observations, we tested a model wherein $L j N F-Y A 1$ works downstream from and is regulated by $L h k l$-dependent signaling to mediate nodule differentiation.

\section{$n f-y a 1-2$ attenuates the snf2-dependent spontaneous nodule formation.}

In L. japonicus, the presence of snf2 confers formation of spontaneous nodules (Tirichine et al. 2006a, 2007). This was also observed in our experiments, in which uninoculated snf2 plants developed large, spontaneous nodules (Fig. 5A and F). Except for the absence of rhizobia, these empty structures displayed all features of genuine nodules, including welldeveloped peripheral vasculature and the presence of both large and smaller cells, with the latter containing significant starch deposits (Fig. 5B and C). By contrast, the snf2 $n f-y a l-2$ double mutant formed only small nodule bumps (Fig. 5D and F) that failed to grow to the stage at which the root epidermis becomes dislodged. Deprived of vasculature, these nodule bumps were composed of uniform, small cells, showing no evidence of differentiation (Fig. 5E). In the absence of M. loti, $n f-y a l-2$ roots were devoid of spontaneous nodulation events (Fig. 5F).

These results highlight the indispensable role of $L j N F$-YAI during nodule differentiation, downstream from LHK1 and the initial cell divisions. Thus, the $l h k l-1$ mutation would be expected to be epistatic to $n f-y a l-2$, which was tested by evaluating the nodulation phenotype of the lhkl-1 nf-yal-2 double mutant.

\section{lhk1-1 $n f-y a 1-2$ reveals a novel infection phenotype.}

Both lhk1-1 (Murray et al. 2007) and $n f-y a l-2$ (Fig. 3) are able to form NP and nodules. In $l h k l-1$, nodule formation is delayed and depends on prior, local infection of the root cortex by 
M. loti (Held et al. 2014). When examined 21 dai, however, the lhkl-1 nf-yal-2 double mutant displayed a novel root-infection phenotype in the complete absence of any nodule development.

At 10 and 14 dai, lhkl-1 nf-yal-2 had many microcolonies entrapped within curled root hairs, along with partially or fully elongated eITs, (Fig. 6A), resembling the hyperinfected phenotype of $l h k 1-1$ (Held et al. 2014; Murray et al. 2007). A proportion of eITs terminated at the base of root hair cells with a hugely exaggerated tip swelling, and some infrequent incidents of bacteria being released into the epidermis-cortex intercellular space were also apparent at these earlier stages (Fig. 6B). As in $l h k 1-1$, eITs were occasionally able to pass the $l h k l-1$ $n f$-yal-2 epidermis-cortex interface to become cortical ITs (cITs), and this was associated with limited, cortical cell divisions (Fig. 6C). However, sporadic, massive colonization of the root cortex by cITs, which in $l h k l-1$ leads to limited nodule
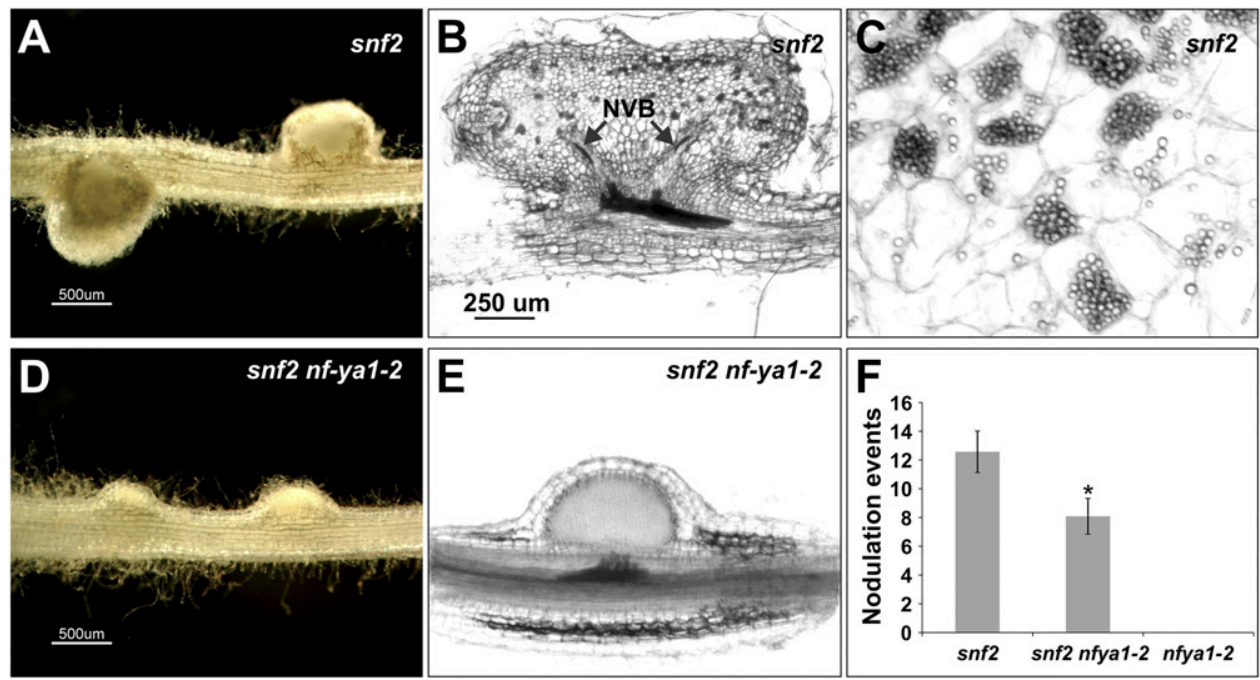

Fig. 5. $n f-y a l-2$ restricts spontaneous nodule formation. Spontaneous nodules, as formed by A, Lotus japonicus snf 2 and $\mathbf{D}$, the snf 2 nf-yal-2 double mutant. B and $\mathbf{E}$, Corresponding spontaneous nodule sections. Note that the largest spontaneous nodule has been selected from among ten independent snf $\mathrm{nf}$-yal-2 roots to generate the image shown in panel E. C, Close-up image of snf2 nodule cells containing large deposits of starch granules. F, Scores of spontaneous nodulation events 8 weeks after sowing; ten individuals were scored for each genotype and averages $\pm 95 \%$ confidence intervals are given. Asterisk $(*)$ indicates statistically significant difference (Student's $t$ test, $P \leq 0.05$ ) from snf2. NVB = nodule vascular bundle.

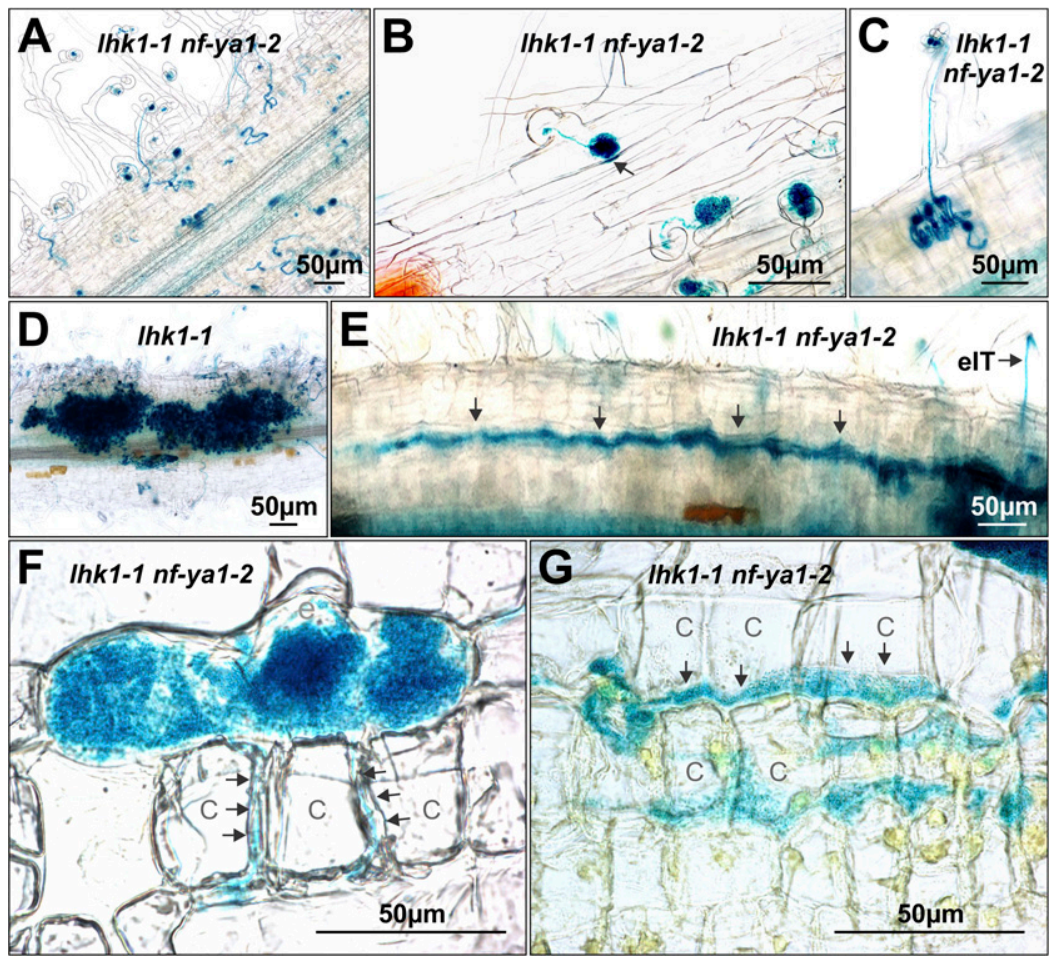

Fig. 6. Mesorhizobium loti is mainly restricted to the extracellular space within the root cortex in the lhkl-1 nf-yal-2 double mutant background. A to C, M. loti infection of $l h k l-1 n f$-yal-2 roots at 10 (A and B) and 14 days after inoculation (dai) (C). D, Hyperinfection of the $l h k l-1$ root epidermis and massive, local migration of infection threads inside the root cortex at 14 dai. $\mathbf{E}$ to G, Extracellular colonization of the lhkl-1 nf-yal-2 root cortex by $M$. loti at 21 dai. E, Note an extended $M$. loti infection strand that follows the longitudinal axis of the $l h k l-1$ nf-yal-2 root. F, A close-up image of the $l h k l-1$ nf-yal-2 root epidermis showing the presence of $M$. loti inside the epidermal cell and also within the intercellular spaces (arrows) of the subepidermal cortex. G, A close-up image of the lhk1-1 nf-yal-2 root cortex showing intercellular infection strands formed by $M$. loti. eIT $=$ epidermal infection thread and $\mathrm{c}=$ root cortical cell. 
formation events (Fig. 6D), was not observed in $l h k l-1$ nf-yal2. Nonetheless, at 21 dai, the $l h k 1-1 n f-y a l-2$ root cortex was colonized by $M$. loti, which instead formed intercellular infection strands (i.e., loose bacteria present in between cells) that primarily followed the longitudinal axis of the root (Fig. 6E), a phenotype rarely observed in wild type or the $l h k l-1$ and $n f$ yal-1 single mutants. Although cortical cells that were abutted by these extracellular bacteria underwent at least one anticlinal cell division, incipient NP and, hence, nodules were not formed and $M$. loti failed to penetrate inside them (Fig. 6F and G).

\section{Downstream targets of LjNF-YA1.}

To gain further insight into the role of LjNF-YA1 during determinate nodule differentiation, a microarray experiment aimed at identifying downstream targets for this presumed

$\square$ har1-1 vs. har1-1 nf-ya1-1 $\square$ wild type vs. nf-ya1-1 $\square$ har1-1 vs. har1-1 nf-ya1-2 $\square$ wild type vs. nf-ya1-2

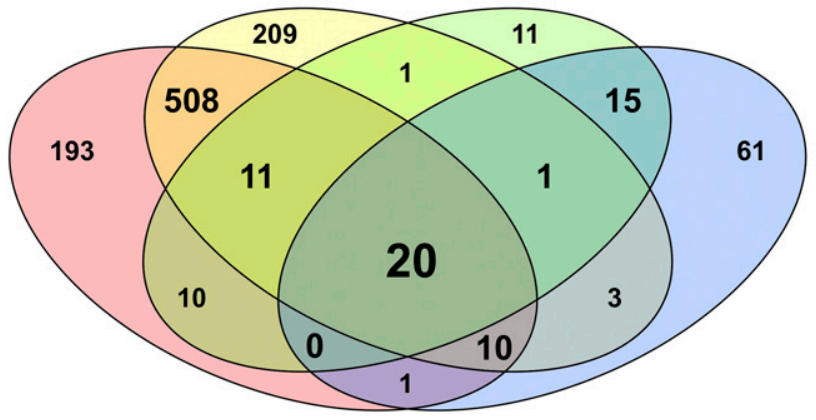

Fig. 7. A Venn diagram showing a subset of differentially expressed probes identified by a microarray approach. Numbers reflect probe sets that show significant ( $\geq 2$-fold at $P \leq 0.05$ ) expression changes between the indicated genotypic contrasts. The 20 probe sets that show significant expression changes in all four comparisons correspond to 17 predicted Lotus japonicus genes. transcriptional factor was carried out using Affymetrix L. japonicus GeneChip. The gene expression levels in roots of wild type and harl-1 parental lines, at 4 dai with $M$. loti, were compared with either $n f$-yal-1 and $n f$-yal-2 single mutants or harl-1 nf-yal-1 and harl-1 nf-yal-2 double mutants, respectively. We reasoned that a subset of genes for which expression is affected by $n f-y a l$ mutations at this relatively early stage after inoculation should emerge as common across all four comparisons, and the presence of the harl-1 allele could accentuate more subtle differences. Assuming at least two fold changes in expression levels at $P \leq 0.05$, genes corresponding to 549 and 36 probe sets could be attributed to the $n f-y a l$ mutations in the harl-1 and wild-type backgrounds, respectively (Fig. 7; Supplementary Table S1). However, concurrent with the analysis of the microarray data, an RNAseq experiment performed in our laboratory revealed that the steady-state level of the LjNF-YAI mRNA was significantly upregulated in uninoculated roots of harl-1 in comparison with the equivalent wild-type samples (E. Zimmerman, S. U. Anderson, J. Stougaard, and K. Szczyglowski, manuscript in preparation). Being expressed ectopically in harl-1 roots in the absence of $M$. loti, LjNF-YA1 is likely to target genes that are not associated with nodule formation, which complicates the interpretation of the harl-1-associated microarray data. Therefore, for the purpose of this work, only 17 genes (corresponding to 20 probe sets) that were deemed as being differentially expressed in wild type versus single mutant comparisons and showed similar expression changes in the double mutants were further considered (Table 1). The gene corresponding to probe chr4.TM0851.2.1_at was included in this common (core) set because changes in expression of this gene were significant for the $P$ value criterion in all four comparisons while falling only marginally outside the twofold threshold in one of the two double mutants (i.e., harl-1 versus harl-1 nf-yal-1, for which a 1.84-fold decrease in the expression level was recorded). These 17 genes, which were expressed at lower levels

Table 1. The core, target gene set for NF-YA1, as defined by the microarray experiment

\begin{tabular}{|c|c|c|}
\hline Probe ID $^{\mathbf{a}}$ & Gene ID (v. 3.0) & Presumed function \\
\hline \multicolumn{3}{|l|}{ Signaling } \\
\hline CM0584.15.1_at & Lj6g3v0959410.1 & SHI/STY-like protein 1 \\
\hline Ljwgs_008021.2_at* & Lj0g3v0059359.1 & SHI/STY-like protein 2 \\
\hline Ljwgs_022749.1_s_at* & $\mathrm{Lj} 2 \mathrm{~g} 3 \mathrm{v} 1728900.1$ & SHI/STY-like protein 3 \\
\hline Ljwgs_011361.1_at & $\mathrm{Lj} 2 \mathrm{~g} 3 \mathrm{v} 1455120.1$ & AP2-like ethylene-responsive transcription factor \\
\hline Ljwgs_029578.1_s_at & Lj3g3v2888290.1 & S-locus lectin protein kinase family protein \\
\hline chr3.CM0152.8_at* & Lj3g3v2888290.1 & S-locus lectin protein kinase family protein ${ }^{\mathrm{b}}$ \\
\hline chr1.CM0295.68_at* & Lj1g3v4515410.1 & G1L4-like probable transcriptional regulator; short hypocotyl 4-like \\
\hline TC15698_at* & Lj1g3v4515410.1? & G1L4-like probable transcriptional regulator; short hypocotyl 4-like \\
\hline chr1.TM0805.9.1_at* & Lj1g3v3729250.1 & BAG-family-like, ubiquitin domain containing protein \\
\hline chr4.TM0851.2.1_at * & Lj4g3v1237990.1 & Auxin canalization-like/VAN3-binding protein (VAB) \\
\hline \multicolumn{3}{|l|}{ Cell growth/divisions } \\
\hline chr1.CM0121.32_s_at & Lj1g3v2264900.1, Lj1g3v2264910.1 & Ornithine decarboxylase \\
\hline gi34495196_at & $\mathrm{nf}^{\mathrm{e}}$ & Ornithine decarboxylase \\
\hline chr2.CM0060.76_at & Lj0g3v0047169.1 & AMN1-like protein \\
\hline \multicolumn{3}{|l|}{ Cell-wall modification } \\
\hline Ljwgs_010358.2_at** & Lj5g3v0670070., Lj5g3v0670070.2 & Pectate lyase-like protein \\
\hline Ljwgs_016679.1_at* & Lj5g3v0670070.1, Lj5g3v0670070.2 & Pectate lyase-like protein ${ }^{\mathrm{d}}$ \\
\hline TM1040.6.1_at & Lj0g3v0019969.1, Lj0g3v0019969.2 & Glucan endo-1,3- $\beta$-glucosidase \\
\hline TM0936.13_at* & Lj0g3v0156149.1 & CASP-like protein \\
\hline \multicolumn{3}{|l|}{ Metabolism } \\
\hline chr5.TM1077.34_at* & Lj5g3v0670650.1, Lj5g3v0670760.1, Lj5g3v0670760.2 & Nodulin/glutamate-ammonia ligase-like protein \\
\hline Ljwgs_037651.1_at* & $\mathrm{Lj} 5 \mathrm{~g} 3 \mathrm{v} 2182110.1$ & Alcohol dehydrogenase \\
\hline \multicolumn{3}{|l|}{ Unknown } \\
\hline chr4.CM0046.23.1_at & $\mathrm{Lj} 4 \mathrm{~g} 3 \mathrm{v} 2616100.1$ & Unknown protein \\
\hline chr5.CM0200.5_at & Lj5g3v2133810.1 & HMA domain-containing protein \\
\hline
\end{tabular}

a Asterisks (*) denote probes with nodule-enhanced or nodule-specific expression patterns, as reported in the Lotus japonicus Gene Expression Atlas.

b Same as Ljwgs_029578.1_s_at.

c Likely the same as chr1.CM0295.68_at.

d Same as Ljwgs_010358.2_at.

$\mathrm{e} \mathrm{nf}=$ no corresponding gene in v.3.0. 
in the mutants than in the wild type, fell into five functional classes, including signaling, cell growth and division, cell-wall modification, metabolism, and unknown categories (Table 1). Interestingly, three of eight genes in the signaling category were found to represent members of the predicted $L$. japonicus SHI/STY gene family, which, in Arabidopsis, regulates development of various lateral organs (Ståldal et al. 2012). We chose to analyze these three genes further in order to validate the microarray data and also to advance the understanding of the functional significance of $L j N F-Y A l$ during nodule formation.

\section{STY genes are likely direct targets of NF-YA1 and} are essential for nodule development.

Quantitative reverse transcription-polymerase chain reaction (qRT-PCR) comparisons of STY1, STY2, and STY3 mRNA levels in wild-type and $n f-y a l-2$ roots, at 4 dai with $M$. loti, showed

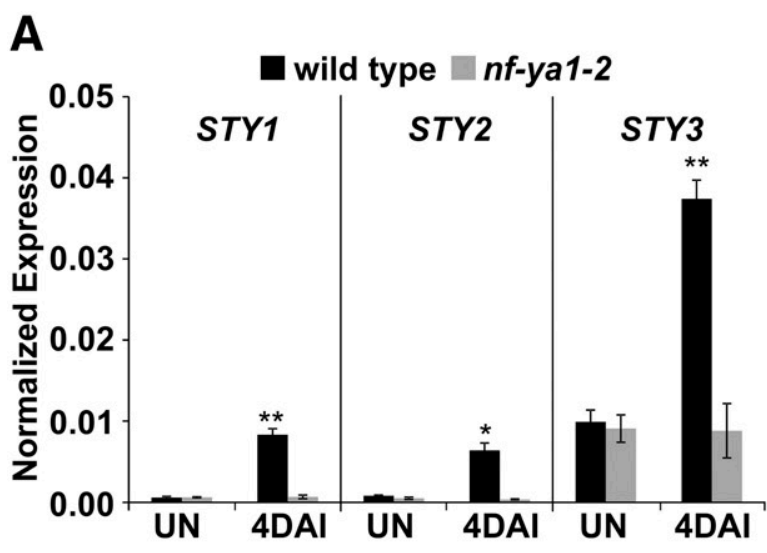

C

B

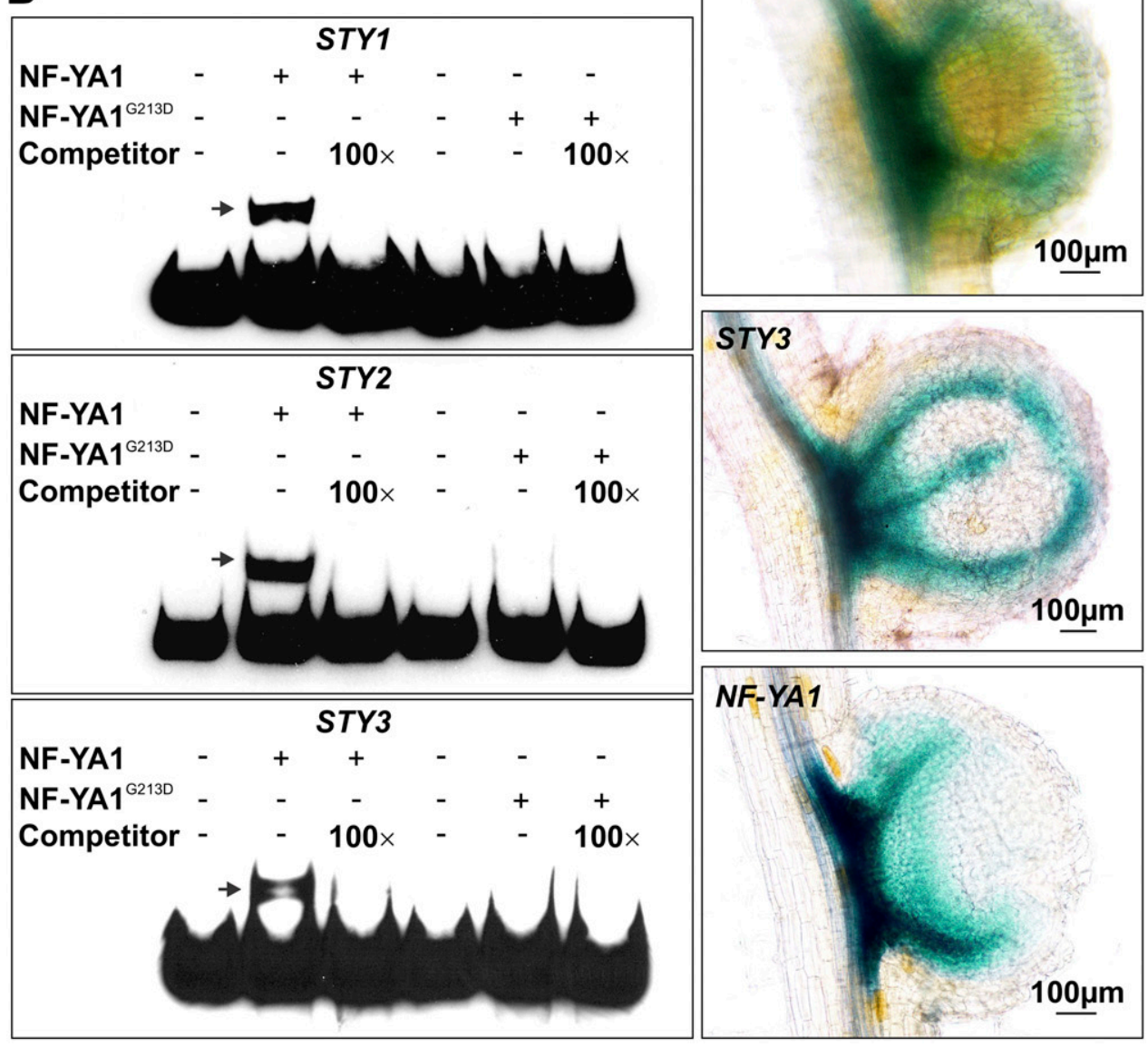

Fig. 8. NF-YA1 mediates $S T Y$ gene expression during nodule development. A, Quantitative reverse transcription-polymerase chain reaction analysis of the $S T Y 1, S T Y 2$, and STY3 mRNAs in Lotus japonicus wild-type and $n f-y a 1-2$ mutant roots. UNR = uninoculated roots harvested 7 days after sowing; $4 \mathrm{DAI}=$ roots harvested 4 days after inoculation (dai) with Mesorhizobium loti. Average values for three biological replicates \pm standard error are given. Asterisks indicate statistically significant differences (one asterisk [*], $P \leq 0.05$; two asterisks [**], $P \leq 0.01$ ) in expression between wild type and mutants. B, Electrophoretic mobility shift assays show specific binding of NF-YA1 to STY gene promoters in vitro. The migration of biotinylated STY1, STY2, and STY3 promoter fragments in the absence (-) or the presence $(+)$ of $1 \mu \mathrm{g}$ of purified FLAG-NF-YA1 wild type or FLAG-NF-YA1 ${ }^{\mathrm{G} 213 \mathrm{D}}$ mutant DNA-binding domain is shown. The corresponding, nonlabeled, wild-type probe in 100-fold molar excess $(100 \times)$ relative to the biotinylated probes have been added as competitors. Arrows indicate the specific binding of the wild-type FLAG-NF-YA1 protein. C, Transgenic hairy roots showing GUS reporter activity, as driven by the STY1, STY2, and STY3 promoters. Images of nodules were taken 21 dai with M. loti. The activity of the NF-YA1 promoter is shown for comparison. 
significant upregulation of the three genes in the wild type that was absent in the mutant (Fig. 8A). This is consistent with the microarray data, confirming that elevated expression levels of the $S T Y$ genes during early symbiotic events depend on the presence of intact NF-YA1. We subsequently tested whether NF-YA1 could interact with $S T Y 1, S T Y 2$, and $S T Y 3$ promotors by performing electrophoretic mobility shift assays (EMSA). Such interaction would be expected if $S T Y$ s constitute direct targets of NF-YA1-dependent regulation. The DNA-binding domain of the LjNF-YA1 protein was able to specifically bind to promoters of the three $S T Y$ genes in vitro. By contrast, the NF-YA $1^{\mathrm{G} 213 \mathrm{D}}$ mutant protein, carrying the $n f-y a l-2$ version of the DNA-binding domain (Fig. 2), could not do so (Fig. 8B). While supporting the specificity of the interaction in vitro, this also provided a plausible explanation for the $n f-y a l-2$ mutant symbiotic phenotype. We further reasoned that if NF-YA1 binds to STY1, $S T Y 2$, and STY3 promoters in vivo, their expression domains would be expected to overlap in nodules. Indeed, when examined in hairy roots 21 dai with $M$. loti, the three $S T Y$ promoters directed the GUS reporter activity to nodule vascular bundles, which mirrors the NF-YAl expression domain in L. japonicus nodules (Fig. 8C).

To begin testing the hypothesis that STY proteins mediate, at least in part, the effect of NF-YA1 on nodule development, we made a chimeric construct composed of the L. japonicus STY3 coding region translationally fused with a DNA fragment encoding the 12-amino acid-long ERF-associated amphiphilic repression (SRDX) domain. The SRDX domain would be expected to convert the presumed STY3 transcriptional activator into a dominant transcriptional repressor, as previously documented for several different transcriptional factors (Hiratsu et al. 2003).

The STY3::SRDX mRNA was expressed in transgenic hairy roots formed on wild-type L. japonicus shoots under the Ubiquitin $\left(U B I_{P r o}\right)$ and $L j N F-Y A 1$ promoters. The green fluorescent protein (GFP) fluorescent marker was used to identify cotransformation events. In the presence of $U B I_{P r o}: S T Y 3:: S R D X$, only nonfluorescing hairy roots were formed, indicating a detrimental effect of the construct. GFP-positive hairy roots were recovered from the empty vector control and $L j N F-Y A 1_{P r}: S T Y 3:: S R D X$ transformations and their nodulation phenotypes were evaluated 21 dai with $M$. loti. While the empty vector-transformed hairy roots showed the wildtype nodulation $(\overline{\mathrm{x}}=8.6 \pm 2.1 ; n=28)$, the presence of $L j N F$ YA1 Pro:STY3::SRDX led to a low nodulation phenotype $(\overline{\mathrm{x}}=1.5 \pm$ 0.8 ). Of 28 independent hairy root systems transformed with $L j N F$ YA1Pro:STY3::SRDX, 13 did not form nodules at all, resembling the prevalent symbiotic phenotype of hairy roots formed on $n f-y a 1-2$ shoots, while the remaining 15 showed a low-nodulation phenotype that included small and regular-size nodules.

\section{DISCUSSION}

Here, we show that the $L$. japonicus genome contains a family of at least nine $L j N F-Y A$ genes, with $L j N F-Y A 1$ displaying a $M$. loti inoculation-dependent expression pattern and being essential for the normal development of functional, nitrogen-fixing root-nodule symbiosis. Our observations confirm that deleterious mutations at the LjNF-YAl locus attenuate nodule development in L. japonicus. Refining the previously published RNAisilencing data (Soyano et al. 2013), we demonstrate that the developmental block imposed by $n f-y a l$ mutations occurs primarily at the NP stage, after the first cell divisions but prior to nodule differentiation, including cell enlargement and vascular bundle formation. Our transcriptomic data suggest that this negative effect of $n f$-yal mutations on symbiosis is, at least in part, due to impaired regulation of $S T Y 1, S T Y 2$, and $S T Y 3$ genes identified by this work as likely direct targets of the NF-YA1dependent regulation.

\section{NF-YA1 is likely to work partially redundantly} to mediate nodule formation in $\mathbf{L}$. japonicus.

When analyzed, at 21 dai with $M$. loti, all four $n f$-yal mutant lines had many small NP, but a few wild type-looking nodules were also formed, which indicates that a block imposed by the corresponding mutations is sometimes overcome. Considering the similar symbiotic defects in four independent $n f$-yal allelic mutant lines analyzed, including the two LORE1 insertion lines that carry premature stop codons and $n f-y a 1-2$, which encodes the NF-YA ${ }^{\text {G213D }}$ protein that has apparently lost its DNA-binding activity (Fig. 8B), this is likely due to the presence of genes that operate in a partially redundant manner. The L. japonicus gene atlas data show that several NF-YA genes, including LjNF-YA4 (LjGEA probe ID: chr1.CM0361.18_at), the closest paralogue of $L j N F-Y A 1$ and a likely ortholog of $M t N F-Y A 2$, are expressed in uninoculated roots and, also, to some degree in nodules, although the steady-state levels of their corresponding mRNAs appear to be, at most, only slightly affected by $M$. loti infection (Verdier et al. 2013). Work is in progress to define whether $L j N F-Y A 4$, singly or in combination with other $L j N F-Y A$ genes, contribute to the presumed, partial redundancy of $L j N F-Y A l$ functions during nodule development and if this is similar to what has been described for $M t N F-Y A 1$ and MtNF-YA2 (Laloum et al. 2014). Our data indicate that $M t N F-Y A l$ is able to rescue the symbiotic defect of $n f-y a l-2$. Hence, in spite of forming different types of nodules, MtNF-YAI and LjNF-YA1 must be functionally equivalent in L. japonicus.

\section{The NF-YA1 infection puzzle?}

Although activity of the $L j N F-Y A 1$ promoter is detectable at the initial stages of the interaction (Fig. 4), no early symbiotic defects were apparent in any of the L. japonicus nf-yal single mutants and NP formation was initiated in a timely manner. Furthermore, neither eIT development nor the ability to form cITs appeared to be perturbed by $n f-y a l$ mutations. The wildtype infection phenotype of $n f-y a l$ mutants is consistent with the results of Soyano et al. (2013), who showed that RNAi of LjNFYAl in L. japonicus hairy roots had no effect on eIT formation, although the status of cITs was not reported. Development of cITs in L. japonicus requires at least some level of cytokinin and NIN-dependent activation of the subtending root cortex (Held et al. 2014; Miri et al. 2016; Yoro et al. 2014). Our phenotypic observations, in particular the presence of cortical cell divisions along with cIT formation, indicate that this signaling process must be operational in L. japonicus $n f$-yal mutants.

By contrast, the Mtnf-yal-1 mutation in Medicago truncatula was associated with misshapen and enlarged eITs that were prematurely arrested within root hairs and had twofold thinner cell walls (Laporte et al. 2014). Furthermore, unlike L. japonicus $n f$-yal mutants, Mtnf-yal-1 was found to develop six times more eITs, as compared with the wild-type control. Interestingly, silencing of MtNF-YA2 in the Mtnf-yal-1 mutant background restricted this presumed compensatory effect, with the composite plants (i.e., Medicago truncatula nf-yal-1 plants with transgenic hairy roots expressing the $M t N F-Y A 2$ silencing construct) forming only a few ITs that were almost all arrested within root hairs (Laloum et al. 2014). As previously stated by others, these results show that, while functioning in a partially redundant manner, the MtNF-YAl-dependent regulation is important for the symbiotic infection in Medicago truncatula (Laloum et al. 2014; Laporte et al. 2014). In contrast, we show here that, in L. japonicus, $L j N F-Y A 1$ is dispensable for this process (Fig. 3). This could reflect different requirements for symbiotic infection of determinate versus indeterminate nodules in L. japonicus and Medicago truncatula, respectively. However, in common bean, which like L. japonicus forms determinate nodules, RNAi silencing of $P v N F-Y C 1$ significantly reduced the number of eITs and affected their progression inside the root cortex (Zanetti et al. 
2010). Thus, an NF-Y transcription factor containing the PvNFYC1 subunit is likely important for rhizobial infection during determinate nodule development in common bean.

If LjNF-YA1 participates in the regulation of $M$. loti infection, this would have to be through a mostly or fully redundant function. The unusual infection phenotype seen in the lhkl-1 nf-yal-2 double mutant (Fig. 6) might be indicative of the former. The $l h k 1-1$ mutation imposes a significant block that halts the majority of eITs from progressing into the root cortex (Miri et al. 2016; Murray et al. 2007). This is manifested in both $l h k 1-1$ and the lhkl-1 nf-yal-2 double mutant as the presence of swollen IT tips at the root epidermis-cortex interface (Fig. 6B), although not all eITs whose growth has been stalled in either of the mutants display this feature. In the $l h k l-1$ $n f$-yal-2 double mutant, release of $M$. loti from ITs into the intercellular root cortical space was apparent at 21 dai (Fig. 6E to $\mathrm{G})$. This is likely the result of eITs that had managed to traverse root hair cells but failed to transit to cITs and became disintegrated. Such relatively wide-spread release and subsequent migration of $M$. lot $i$ within the root intercellular compartment has not been observed in the $n f-y a l-2$ single mutant, nor is it a feature of $l h k l-1$. The latter shows that the role of LjNF-YA1 during nodulation is not completely dependent on LHK1. It is, therefore, conceivable that the $n f-y a l-2$ mutation directly or indirectly weakens the integrity of ITs and that this is exacerbated by hindered IT growth in the $l h k 1-1$ background, resulting in the release of bacteria. Whether this is related to diminished integrity of the IT cell wall, as reported for Mtnfyal-1 (Laporte et al. 2014), remains to be determined.

Importantly, the phenotype of lhkl-1 nf-yal-2 demonstrates that, once beyond the root epidermis, $M$. loti can be an avid extracellular endophyte, with the ability to colonize the root interior by propagating through infection strands within the root intercellular space. This $M$. loti trait becomes apparent in the $l h k 1-1 n f-y a l-2$ double mutant, in which the ability to form eITs appears to be intact but entry into cortical cells has been compromised. The fact that the lhkl-1 nf-yal-2 double mutant does not form nodules, in contrast to the corresponding single mutants, extends our previous observations and further demonstrates the requirement for a local, massive entry of $M$. lot $i$ inside root cortical cells in order for $l h k 1-1$ to develop nodules (Held et al. 2014). Apparently, formation of extracellular, cortical infection strands (Fig. 6G) is not sufficient for nodule formation in the absence of functional LHK1and NF-YA1.

\section{$n f-y a 1$ mutations attenuate the cortical program for nodule formation prior to differentiation.}

Evaluation of symbiotic phenotypes of hairy roots associated with the RNAi of $P v N F-Y C 1$ or its interacting partner, Scarecrow-like13 Involved in Nodulation (SIN1), led to the conclusion that the corresponding proteins might act in common bean to activate cortical cell divisions for NP formation (Battaglia et al. 2014; Zanetti et al. 2010). Similarly, RNAimediated downregulation of LjNF-YAl gene expression in hairy roots of both the L. japonicus wild type and a gain-of-function $\mathrm{CCaMK}^{\mathrm{T} 265 \mathrm{D}}$ mutant demonstrated an early inhibition of cortical cell divisions for NP formation, with the majority of composite plants developing no nodules (Soyano et al. 2013). The mainly non-nodulating phenotype of $n f-y a l-2$ hairy roots is consistent with these earlier observations. However, all L. japonicus $n f-y a l$ mutants tested in this study developed a large number of small NP and the snf2 $n f-y a l-2$ double mutant was capable of forming underdeveloped nodule bumps in the absence of M. loti, indicating that, in L. japonicus, hairy roots exaggerate the $n f-y a l-2$ mutant symbiotic phenotype.

In comparison with mostly very small NP of $M$. lotiinoculated $n f$-yal single mutants, spontaneously formed nodule bumps of snf2 $n f-y a l-2$ appeared to be more advanced in terms of the extent of cell divisions. It may be that the constitutive activity of $\operatorname{snf} 2$ accounts for this phenotypic difference. Regardless, even the largest spontaneous nodulation event in snf2 $n f-y a 1-2$ lacked some key features of nodule differentiation, including the presence of enlarged cells and nodule vasculature (Fig. 5). We conclude, therefore, that, during determinate nodule development in L. japonicus, LjNF-YA1 becomes indispensable either downstream from the initial cortical cell divisions at the stage of cell division maintenance (Suzaki et al. 2012), during the transition of young NP cells from divisions to differentiation, or both. Given the activity pattern of the $L j N F$ YA1 promoter, it is also likely that LjNF-YA1 partakes in mediating earlier symbiotic events, prior to or concomitant with the initiation of cell divisions, but this must be through one or more redundantly operating functions. In Medicago truncatula, the induction of MtNF-YA1 and MtNF-YA2 in root hairs of rhizobially inoculated plants is accompanied by the activation of auxin and cell-cycle markers, suggesting that infection may require engagement of NF-Ys and cell-cycle machinery (Breakspear et al. 2014).

\section{NF-YA1 regulates $S T Y$ gene expression.}

Among 17 genes defined by this work as likely being regulated by NF-YA1 (Table 1), three members of the L. japonicus SHI/STY zinc-finger transcription factor gene family, i.e., STY1, $S T Y 2$, and STY3, were characterized as potential direct targets. We show that their expression is significantly up-regulated in L. japonicus roots early on upon $M$. loti infection and associates with vascular bundles in mature nodules. In Arabidopsis thaliana and Physcomitrella patens, STY proteins have been shown to regulate various developmental processes in a redundant manner, including formation of lateral roots and flowers and leaf venation (Baylis et al. 2013; Kuusk et al. 2002, 2006; Smith and Fedoroff 1995). Our data suggest that they might also play an essential role during symbiotic root nodule formation in L. japonicus.

Downstream targets of L. japonicus STY1, STY2, and STY3 are currently unknown but in Arabidopsis, STY1 was shown to regulate different transcription factors and genes associated with cell expansion and auxin biosynthesis (Eklund et al. 2010a and b; Sohlberg et al. 2006). The latter has been demonstrated to be carried out by STYs through direct transcriptional activation of YUC genes (Eklund et al. 2010a and b; Sohlberg et al. 2006), which encode the indole-3-pyruvic acid (IPyA) decarboxylase, a rate-limiting enzyme that works downstream from tryptophan aminotransferases in the IPyA auxin biosynthesis pathway (Cheng et al. 2006; Zhao 2012).

Several independent studies have shown that, during nodule formation, auxin response maxima are generated downstream from NF perception and the resulting cytokinin signaling (Deinum et al. 2015; Mathesius 2008; Mathesius et al. 2000; Plet et al. 2011; Suzaki et al. 2012). In L. japonicus, initiation of auxin activity accompanies the initial cortical cell divisions for NP formation but has also been linked with their maintenance and with the development of the nodule vasculature and lenticels (Suzaki et al. 2012; Takanashi et al. 2011). A model has been proposed in which local accumulation of auxin within $M$. loti-inoculated $L$. japonicus roots originates as a result of the LHK1-dependent NIN activation; however, the mechanism by which NIN regulates auxin is unknown (Suzaki et al. 2012). One possibility is that NF-YA1, which is transcriptionally activated by NIN in the root cortex (Soyano et al. 2013) partakes in the generation of local auxin maxima by mediating the STY1, $S T Y 2$, and $S T Y 3$ gene expression, which aids in the differentiation of the determinate nodule structure, including cell expansion and formation of nodule vascular bundles. However, 
due to the lack of a clear response of the $Y U C$ genes in our microarray experiment, this idea needs to be further examined.

Interestingly, downregulation of another gene, $L j 4 g 3 v 1237990$, in both $n f-y a l-1$ and $n f$-yal-2 mutants (Table 1) might also be of relevance in the context of auxin signaling. Predicted as legume-specific in the Lotus japonicus gene expression atlas database, $L j 4 g 3 v 1237990$ encodes a protein that contains the auxin canalization domain (pfam05073) and plant plekstrinhomology region (pfam08458). These features are shared by the Arabidopsis FORKED1/VAB (Hou et al. 2010) and other VAN3binding (VAB)-like proteins from various species, including Glycine max (XP_014630987) and Medicago truncatula (Medtr5g012870). VAN3 is an adenosine diphosphate-ribosylation factor guanosine triphosphatase activating protein (Koizumi et al. 2005). Together with the COTYLEDON VASCULAR PATTERN2 inositol polyphosphate 5'-phosphatase and VAB, VAN3 functions in Arabidopsis in vascular pattern formation by influencing localization of the PIN1 auxin efflux carrier (Caño-Delgado et al. 2010; Hou et al. 2010; Koizumi et al. 2000; Naramoto et al. 2009). A similar mechanism might be relevant during differentiation of nodule vasculature in L. japonicus and our data suggest that NF-YA1 could be a regulator of this process. In Arabidopsis, expression of FORKEDI/VAB was shown to be responsive to auxin levels (Hou et al. 2010). Future research will have to establish whether the reduced expression level of $L j 4 g 3 v 1237990$, which we named $L j V A B$-like 1 or $L j V A B L 1$, correlates with a local deficiency in auxin transport in $L$. japonicus NP deprived of NF-YA1 and if this, indeed, contributes to the attenuated development of $n f-y a l$ nodules.

\section{MATERIALS AND METHODS}

\section{Plant materials, growth conditions, and assessment of symbiotic phenotypes.}

The L. japonicus $n f$-yal mutants were identified from a screen for genetic suppressors of the harl-1 hypernodulation phenotype, with the originally selected LjS47-A and LjS95-E lines (Murray et al. 2006) corresponding to harl-1 nf-yal-1 and harl-1 nf-yal-2, respectively. Three additional mutant alleles, namely $n f-y a 1-3, n f-y a 1-4$, and $n f-y a 1-5$, were identified from the L. japonicus LORE1 retrotransposon mutant resource (line numbers 30004771, 30003811, and 30003445, respectively) (Fukai et al. 2012; Urbański et al. 2012). Although not analyzed further, $n f-y a 1-5$ carries the insertion within exon $7,1,520 \mathrm{bp}$ downstream from the NF-YAl initiation codon, and showed the same defective symbiotic phenotype as other $n f$-yal mutant plants described in this work.

Seed germination, soil growth conditions, and evaluation of symbiotic phenotypes were as previously described (Wopereis et al. 2000), except that microscopic observations were made under higher, 20x magnification in order to capture even the smallest nodule formation events.

For studying the response of L. japonicus wild type, lhkl-1, and nin-8 plants to exogenous cytokinin, roots were collected from 10-day-old plants that had been incubated for $6 \mathrm{~h}$ in the presence of $50 \mathrm{nM}$ 6-benzylaminopurine, as described in Murray et al. (2007).

\section{Map-based cloning of the $N F-Y A 1$ locus.}

The rough map position of the causative locus was initially determined using two sets of 30 mutants, each selected from the two independent $\mathrm{F} 2$ segregating populations obtained by crossing LjS47-A (harl-1 nf-yal-1) and LjS95-E (harl-1 nf-yal-2) with the polymorphic MG20_harl-1 introgression line (Murray et al. 2006). In both cases, the mutated locus was determined to be located on chromosome 5 between markers TM0494 and TM0471 in the L. japonicus genome. Allelic tests between $n f$ yal-1 and $n f-y a l-2$ confirmed that the same locus was affected in both mutant lines. To further delineate the flanking region, 960 selected F2 harl-1 nf-yal-2 mutant individuals were used to analyze recombination events. The simple sequence repeat markers, as selected from the publicly available $L$. japonicus genome website, were used for the linkage analysis.

\section{Characterization of the $N F-Y A I$ mRNA.}

The L. japonicus 'Gifu' $N F-Y A 1$ cDNA was amplified from the total RNA derived from 21-day-old nodules, using the ThermoScript RT-PCR system (Invitrogen). To obtain the full length NF-YA1 mRNA sequence, $5^{\prime}$ and $3^{\prime}$ rapid amplification of cDNA ends was performed, using the FirstChoice RLMRACE kit (Ambion). The PCR conditions for amplifying the full-length $N F-Y A l$ mRNA using the $N F-Y A l$-cDNA full F1 and $N F-Y A 1$-cDNA full R1 primers were as follows: $94^{\circ} \mathrm{C}$ for $5 \mathrm{~min}$, followed by 30 cycles of $94^{\circ} \mathrm{C}$ for $30 \mathrm{~s}, 58^{\circ} \mathrm{C}$ for $30 \mathrm{~s}$, $68^{\circ} \mathrm{C}$ for $4 \mathrm{~min}$, with a final extension for $7 \mathrm{~min}$ at $68^{\circ} \mathrm{C}$. To determine the extent of the $n f-y a l-1$ specific sequence deletion (Fig. 3), the $n f-y a l-l$ del-F1 and $n f-y a l-l$ del-R1 primers were used. Sequences of primers used are listed in Supplementary Table S2.

\section{In planta complementation assays.}

The L. japonicus and Medicago truncatula NF-YAl genes (including their respective promoter, coding, and 3' UTRs) were amplified using the gene-specific primers. The resulting DNA fragments were recombined into the pKGWD,0 destination vector (University of Ghent Gateway Vectors website) (Karimi et al. 2002). The resulting binary vectors were introduced by Agrobacterium rhizogenes-mediated transformation to generate transgenic hairy roots on nontransgenic L. japonicus nf-yal-2 mutant shoots, following the previously established procedure (Murray et al. 2007). The same A. rhizogenes strain carrying an empty vector was used as a negative control. Wildtype and $n f-y a l-2$ shoots that developed hairy roots were transplanted into a sterilized sand and vermiculate mixture and were grown for 5 days prior to $M$. loti inoculation. For each construct and genotype, at least 10 individual plants from two independent experiments were evaluated 21 dai with $M$. loti.

\section{Gene expression analysis using quantitative RT-PCR.}

Total RNA was extracted from various $L$. japonicus 'Gifu' tissues using the Plant/fungi total RNA purification kit (Norgen Biotek). The analysis of RNA quality, cDNA synthesis, and qRT-PCR of the NF-YA1 mRNA were performed as described by Held et al. (2014), using NF-YAl-qPCR-F and NF-YAlqPCR-R primers. qRT-PCR of $S T Y 1, S T Y 2$, and $S T Y 3$ mRNA was carried out using the SsoFast EvaGreen supermix (Bio-Rad) under the following conditions: $95^{\circ} \mathrm{C}$ for $2 \mathrm{~min}$, followed by 45 cycles of $95^{\circ} \mathrm{C}$ for $5 \mathrm{~s}$ and $60^{\circ} \mathrm{C}$ for $30 \mathrm{~s}$. Expression levels were normalized against three reference genes including $U B C, P P 2 A$, and ATPs (Tirichine et al. 2007).

\section{Gene expression analysis using GUS histochemical assay.}

To develop the gene expression localization constructs, the 3.045 and $2.4 \mathrm{~kb} L j N F-Y A 1$ and MtNF-YAl promoter fragments, respectively, were amplified. In addition, 4-kb fragments encompassing the $S T Y 1, S T Y 2$, and $S T Y 3$ promoter regions (position -1 to $-4,000$ in the corresponding genomic sequences, where -1 denotes the first base upstream from the predicted ATG initiation codon) were prepared by gene synthesis (Bio Basic Inc.). These were recombined in the pKGWFS7 destination vector containing GFP/GUS reporter fusion (University of Ghent Gateway vector website), using the GatewayTM technology (Invitrogen). After validation by sequencing, the corresponding vectors were transferred to either Agrobacterium tumefaciens LBA4404 (LjNF-YA1 Pro $_{\text {: }}$ GUS) or to A. rhizogenes 
ARIO (MtNF-YA1 $1_{P r o}: G U S, S T Y 1_{P r o}: G U S, S T Y 2_{P r o}: G U S$, and $\left.S T Y 3_{P r o}: G U S\right)$. Standard transformation protocols were employed to generate either fully transgenic $L$. japonicus plants carrying the LjNF-YAl:GUS promoter gene fusion (Lombari et al. 2005) or nontransgenic L. japonicus shoots with hairy roots expressing other constructs (Murray et al. 2007). At least seven independent fully transgenic L. japonicus plants or 10 independent hairy root systems were carefully inspected to define expression patterns. The staining procedure for detection of the GUS reporter activity was as described previously (Held et al. 2014), except for the nodule section shown in Figure 4F. In the latter case, fully mature nodules derived from transgenic L. japonicus plants carrying $L j N F-Y A 1_{P r o}: G U S$ were embedded in agar and were sectioned to a thickness of $30 \mu \mathrm{m}$, prior to being stained for GUS activity for approximately $30 \mathrm{~min}$, in order to improve the penetrance of the GUS histochemical substrate.

\section{Evaluation of $n f-y a 1-2$ phenotype in the presence of cytokinin loss and gain-of-function alleles.}

An $A$. rhizogenes strain carrying the snf 2 allele integrated within its T-DNA (a gift from J. Stougaard, Aarhus University, Denmark) (Tirichine et al. 2007) was used to induce hairy roots on the L. japonicus wild-type and harl-1, nf-yal-1, nf-yal-2, harl-1 nf-yal-1, and harl-1 nf-yal-2 mutant shoots. The resulting composite plants were grown under sterile conditions in a sand and vermiculate mixture supplemented with the $1 \times$ B\&D nutrient solution (Broughton and Dilworth 1971) containing $0.5 \mathrm{mM} \mathrm{KNO}_{3}$. The number of spontaneous nodules was determined 8 weeks after planting. Similar growth conditions were employed to evaluate spontaneous nodule formation in snf2, nf-yal-2, and snf2 nf-yal-2 mutant plants (Fig. 7) and also to determine steady-state levels of the NF-YA1 mRNA in uninoculated wild-type and $s n f 2$ roots (Fig. 6), except that the latter two root samples were collected 9 days after sowing.

The snf2 nf-yal-2 and lhkl-1 nf-yal-2 double mutant lines were developed through genetic crosses between $n f-y a l-2$ and $\operatorname{snf} 2$ or $l h k 1-1$, respectively. Homozygous double mutants were selected from the corresponding F2 populations, using allelespecific markers for $s n f 2$ (snf2 dCAPS) (Madsen et al. 2010) nf-yal-2, and $l h k l-1$ (nf-yal-2-CAPS-MboI and lhkl-1-CAPSBccI, respectively).

\section{Development of $N F-Y A 1_{P r o}: G U S$ and $N I N_{P r o}: G U S$ lines in $l h k 1-1$ background.}

To evaluate the activity of the LjNF-YAl promoter in the lhkl-1 genetic background, a transgenic line carrying the $L j N F$ $Y A 1_{P r o}: G U S$ reporter (discussed above) was crossed with the homozygous $\operatorname{lhk} 1-1$. Individual plants from a segregating F2 population were screened for GUS activity, and GUS-positive plants were genotyped for the presence of the $l h k l-1$ allele. LjNF-YA $1_{\text {Pro }}$ :GUS plants carrying the homozygous $l h k 1-1$ mutation were selected and F3 plants were used for promoter localization studies. A similar procedure was used to develop a L. japonicus line expressing $N_{\text {IN }}$ :GUS (provided by $\mathrm{J}$. Stougaard, Aarhus University, Denmark) (Radutoiu et al. 2003) in the $l h k l-1$ background.

\section{Microarray gene expression analysis.}

Three biological replicates were generated for each genotype, and root samples were harvested 4 dai with $M$. loti. Total RNA extractions were carried out using TRIZOL reagent (Invitrogen) (Chomczynski and Mackey 1995), followed by genomic DNA removal by DNaseI (Ambion), with an additional column purification with RNeasy MinElute cleanup kit (Qiagen). RNA was quantified using a NanoDrop Spectrophotometer ND-100 (NanoDrop Technologies) and was evaluated for purity with a
Bioanalyzer 2100 (Agilent). The Affymetrix GeneChip Lotus Genome Array (Affymetrix) was used for expression analysis. Probe labeling, using $4 \mu \mathrm{g}$ RNA, array hybridization, and scanning were performed according to the manufacturer's instructions (Affymetrix) for eukaryotic RNA, using a one-cycle protocol for cDNA synthesis. Raw data were normalized by robust multichip averaging, as previously described (Irizarry et al. 2003). Presence and absence calls for probe sets were obtained using the dCHIP algorithm (Li and Wong 2001). Differentially expressed genes in mutants were identified using the associative analysis (Dozmorov and Centola 2003). Type I family-wise error rate was reduced by using a Bonferroni corrected $P$ value (threshold 0.05 ). False discovery rate was controlled by calculating the $q$ value using extraction of differential gene expression (Leek et al. 2006). To identify differentially regulated probe sets, we used a $P$ value threshold of $95 \%$ and at least a twofold difference in transcript expression level. All microarray data were deposited in ArrayExpress under accession number E-MTAB-4970.

\section{EMSA.}

A C-terminal portion of the NF-YAl mRNA encompassing the DB domain (i.e., amino acid residues 184 to 332) was amplified, using the NF-YAI_DB-F and NF-YA1_DB-R primers. Restriction enzyme sites for HindIII and BglII along with three random nucleotides were introduced at $5^{\prime}$ ends of forward and reverse primers, respectively, in order to aid cloning into the pT7-FLAG-2 expression vector (Sigma). The integrity of the resulting $N F-Y A 1 D B-F L A G$ expression plasmid was confirmed by sequencing. To generate the $n f-y a l-2$ version of the same construct, a site-directed mutagenesis was carried out using NF-YAIDB-FLAG (above) as the template and the $5^{\prime}$ phosphorylated forward (5'-AAGGGGATGTGGTGATCGGT TCTTGAACA-3') and reverse (5'-GGCCGGCGCATTGCAT GTAGATGGC-3') primers. The resulting vector was sequenced to confirm the presence of the $n f-y a l-2$ mutation (i.e., A to $\mathrm{G}$ substitution, shown in bold italics in the forward primer). The recombinant NF-YA1 and NF-YA $1^{\mathrm{G} 213 \mathrm{D}} \mathrm{DB}$ domains with C-terminal FLAG tag were produced and purified using ANTIFLAG M2 affinity gel (Sigma), following the manufacturer's instructions.

EMSA assays were carried out using the LightShift chemiluminescent EMSA kit (ThermoFisher). For $S T Y 1$, the region spanning nucleotide positions from $-1,615$ to +88 (where +1 reflects $A$ in the predicted ATG translation initiation codon) was amplified as three overlapping fragments $(-1,615$ to $-1,079$; $-1,101$ to -539 ; and -558 to +88 ). These fragments were biotin end-labeled using the Biotin $3^{\prime}$ end DNA labeling kit (ThermoFisher) and were tested for the binding of NF-YA1DBFLAG in vitro. The middle fragment, $-1,101$ to -539 , which showed binding, was subsequently divided into three additional subfragments, with only the -953 to -729 region demonstrating the specific binding activity. The same -953 to -729 STY1 promoter fragment was used to test for the binding activity of the mutant NF-YA1DB ${ }^{\mathrm{G} 213 \mathrm{D}}$-FLAG. A similar procedure was used to select the STY2 (-357 to -104$)$ and STY3 (-293 to -82$)$ promoter fragments, which were specifically recognized by NF-YA1DB-FLAG in vitro. The corresponding nonlabeled promoter fragments were used as cold competitors.

\section{A dominant negative STY3::SRDX.}

The ubiquitin promoter (Maekawa et al. 2008) was synthesized (Bio Basic Inc.), with attL1 and attR5 recombination sites at its 5' and 3' ends, respectively. A DNA fragment encompassing the entire STY3 coding region (gene ID Lj2g3v1728900.1 [Kazusa Research Institute's L. japonicus database]), translationally fused with the 36-bp sequence for the ERF-associated amphiphilic 
repression domain (superman repression domain X [SRDX]) (Hiratsu et al. 2003), and the attL5 and attL2 recombination sites at the $5^{\prime}$ and $3^{\prime}$ ends, respectively, was also prepared by gene synthesis (Bio Basic Inc.). Similarly, another DNA fragment encompassing the L. japonicus NF-YAl promoter (position -2766 to -1 , gene ID Lj5g3v0841080.1) transcriptionally linked to the $S T Y 3:: S R D X$ coding region (as above) and followed by the NF-YA1 3' UTR gene, was synthesized with attL1 and attL2 sites (Bio Basic Inc.). These DNA fragments were recombined directly into the pKGWD, 0 destination vector, using either the standard or MultiSite Gateway technologies (Invitrogen), giving rise to $U B I_{P r o}: S T Y 3:: S R D X$ and $N F-Y A 1_{P r o}: S T Y 3:: S R D X: N F$ $Y A 13^{\prime} U T R$ vectors. Upon validating the integrity of the vectors by sequencing, they were transferred along with the empty pKGWD,0, used as a negative control, to A. rhizogenes AR1193. The resulting Agrobacterium strains were used to generate transgenic hairy roots on nontransgenic $L$. japonicus wild-type shoots, as described above. The symbiotic phenotype of the composite plants was evaluated 21 dai with $M$. loti by counting nodulation events on GFP-fluorescing hairy roots.

\section{ACKNOWLEDGMENTS}

We thank A. Molnar for his expert help in preparation of figures. This work was supported by grants from Agriculture and Agri-Food Canada Crop Genomics Initiative and National Science and Engineering Research Council of Canada (NSERC grant no. 3277A01) to K. Szczyglowski.

\section{LITERATURE CITED}

Arrighi, J. F., Barre, A., Ben Amor, B., Bersoult, A., Soriano, L. C., Mirabella, R., De Carvalho-Niebel, F., Journet, E. P., Ghérardi, M., Huguet, T. Geurts, R., Dénarié, J., Rougé, P., and Gough, C. 2006. The Medicago truncatula lysine motif-receptor-like kinase gene family includes NFP and new nodule-expressed genes. Plant Physiol. 142:265-279.

Battaglia, M., Rípodas, C., Clúa, J., Baudin, M., Aguilar, O. M., Niebel, A., Zanetti, M. E., and Blanco, F. A. 2014. A nuclear factor Y interacting protein of the GRAS family is required for nodule organogenesis, infection thread progression, and lateral root growth. Plant Physiol. 164:1430-1442.

Baudin, M., Laloum, T., Lepage, A., Rípodas, C., Ariel, F., Frances, L., Crespi, M., Gamas, P., Blanco, F. A., Zanetti, M. E., de Carvalho-Niebel, F., and Niebel, A. 2015. A phylogenetically conserved group of nuclear factor-Y transcription factors interact to control nodulation in legumes. Plant Physiol. 169:2761-2773.

Baylis, T., Cierlik, I., Sundberg, E., and Mattsson, J. 2013. SHORT INTERNODES/STYLISH genes, regulators of auxin biosynthesis, are involved in leaf vein development in Arabidopsis thaliana. New Phytol. 197:737-750.

Breakspear, A., Liu, C., Roy, S., Stacey, N., Rogers, C., Trick, M., Morieri, G., Mysore, K. S., Wen, J., Oldroyd, G. E. D., Downie, J. A., and Murray, J. D. 2014. The root hair "infectome" of Medicago truncatula uncovers changes in cell cycle genes and reveals a requirement for auxin signaling in rhizobial infection. Plant Cell 26:4680-4701.

Broghammer, A., Krusell, L., Blaise, M., Sauer, J., Sullivan, J. T., Maolanon, N., Vinther, M., Lorentzen, A., Madsen, E. B., Jensen, K. J., Roepstorff, P., Thirup, S., Ronson, C. W., Thygesen, M. B., and Stougaard, J. 2012. Legume receptors perceive the rhizobial lipochitin oligosaccharide signal molecules by direct binding. Proc. Natl. Acad. Sci. U.S.A. 109: 13859-13864.

Broughton, W. J., and Dilworth, M. J. 1971. Control of leghaemoglobin synthesis in snake beans. Biochem. J. 125:1075-1080.

Caño-Delgado, A., Lee, J. Y., and Demura, T. 2010. Regulatory mechanisms for specification and patterning of plant vascular tissues. Ann. Rev. Cell Dev. Bi. 26:605-637.

Charpentier, M., Sun, J., Martins, T. V., Radhakrishnan, G. V., Findlay, K., Soumpourou, E., Thouin, J., Véry, A. A., Sanders, D., Morris, R. J., and Oldroyd, G. E. D. 2016. Nuclear-localized cyclic nucleotide-gated channels mediate symbiotic calcium oscillations. Science 352:1102-1105.

Cheng, Y., Dai, X., and Zhao, Y. 2006. Auxin biosynthesis by the YUCCA flavin monooxygenases controls the formation of floral organs and vascular tissues in Arabidopsis. Genes Dev. 20:1790-1799.

Chomczynski, P., and Mackey, K. 1995. Modification of the TRI reagent procedure for isolation of RNA from polysaccharide- and proteoglycanrich sources. Biotechniques 19:942-945.
Combier, J. P., Frugier, F., De Billy, F., Boualem, A., El-Yahyaoui, F. Moreau, S., Vernié, T., Ott, T., Gamas, P., Crespi, M., and Niebel, A. 2006. MtHAP2-1 is a key transcriptional regulator of symbiotic nodule development regulated by microRNA169 in Medicago truncatula. Genes Dev. 20:3084-3088.

Combier, J. P., De Billy, F., Gamas, P., Niebel, A., and Rivas, S. 2008. Trans-regulation of the expression of the transcription factor MtHAP2-1 by a uORF controls root nodule development. Genes Dev. 22:1549-1559.

Corradi, N., and Bonfante, P. 2012. The arbuscular mycorrhizal symbiosis: Origin and evolution of a beneficial plant infection. PLoS Pathog. 8:e1002600.

Deinum, E. E., Geurts, R., Hartog, M., Bisseling, T., and Mulder, B. M. 2015. Computational and Experimental Evidence That Auxin Accumulation in Nodule and Lateral Root Primordia Occurs by Different Mechanisms. Pages 659-668 in: Biological Nitrogen Fixation. F. J deBruijn, ed. John Wiley \& Sons, Inc., Hoboken, NJ, U.S.A.

Desbrosses, G. J., and Stougaard, J. 2011. Root nodulation: A paradigm for how plant-microbe symbiosis influences host developmental pathways. Cell Host Microbe 10:348-358.

Dolfini, D., Gatta, R., and Mantovani, R. 2012. NF-Y and the transcriptional activation of CCAAT promoters. Crit. Rev. Biochem. Mol. Biol. 47:29-49.

Dolfini, D., Zambelli, F., Pedrazzoli, M., Mantovani, R., and Pavesi, G. 2016. A high definition look at the NF-Y regulome reveals genome-wide associations with selected transcription factors. Nucleic Acids Res. 44:4684-4702.

Dozmorov, I., and Centola, M. 2003. An associative analysis of gene expression array data. Bioinformatics 19:204-211.

Eklund, D., Ståldal, V., Valsecchi, I., Cierlik, I., Eriksson, C., Hiratsu, K., OhmeTakagi, M., Sundström, J. F., Thelander, M., Ezcurra, I., and Sundberg, E. 2010a. The Arabidopsis thaliana STYLISH1 protein acts as a transcriptional activator regulating auxin biosynthesis. Plant Cell 22:349-363.

Eklund, D. M., Thelander, M., Landberg, K., Ståldal, V., Nilsson, A., Johansson, M., Valsecchi, I., Pederson, E. R. A., Kowalczyk, M., Ljung, K., Ronne, H., and Sundberg, E. 2010b. Homologues of the Arabidopsis thaliana SHI/STY/LRP1 genes control auxin biosynthesis and affect growth and development in the moss Physcomitrella patens. Development 137:1275-1284.

Fournier, J., Teillet, A., Chabaud, M., Ivanov, S., Genre, A., Limpens, E., Carvalho-Niebel, F. D., and Barker, D. G. 2015. Remodeling of the infection chamber before infection thread formation reveals a two-step mechanism for rhizobial entry into the host legume root hair. Plant Physiol. 167:1233-1242.

Fukai, E., Soyano, T., Umehara, Y., Nakayama, S., Hirakawa, H., Tabata, S., Sato, S., and Hayashi, M. 2012. Establishment of a Lotus japonicus gene tagging population using the exon-targeting endogenous retrotransposon LORE1. Plant J. 69:720-730.

Geurts, R., Xiao, T. T., and Reinhold-Hurek, B. 2016. What does it take to evolve a nitrogen-fixing endosymbiosis? Trends Plant Sci. 21:199-208.

Heckmann, A. B., Sandal, N., Bek, A. S., Madsen, L. H., Jurkiewicz, A., Nielsen, M. W., Tirichine, L., and Stougaard, J. 2011. Cytokinin induction of root nodule primordia in Lotus japonicus is regulated by a mechanism operating in the root cortex. Mol. Plant-Microbe Interact. 24:1385-1395.

Held, M., Hou, H., Miri, M., Huynh, C., Ross, L., Hossain, M. S., Sato, S., Tabata, S., Perry, J., Wang, T. L., and Szczyglowski, K. 2014. Lotus japonicus cytokinin receptors work partially redundantly to mediate nodule formation. Plant Cell 26:678-694.

Hiratsu, K., Matsui, K., Koyama, T., and Ohme-Takagi, M. 2003. Dominant repression of target genes by chimeric repressors that include the EAR motif, a repression domain, in Arabidopsis. Plant J. 34:733-739.

Høgslund, N., Radutoiu, S., Krusell, L., Voroshilova, V., Hannah, M. A., Goffard, N., Sanchez, D. H., Lippold, F., Ott, T., Sato, S., Tabata, S. Liboriussen, P., Lohmann, G. V., Schauser, L., Weiller, G. F., Udvardi, M. K., and Stougaard, J. 2009. Dissection of symbiosis and organ development by integrated transcriptome analysis of Lotus japonicus mutant and wild-type plants. PLoS One 4:e6556.

Hou, H., Erickson, J., Meservy, J., and Schultz, E. A. 2010. FORKED1 encodes a $\mathrm{PH}$ domain protein that is required for PIN1 localization in developing leaf veins. Plant J. 63:960-973.

Irizarry, R. A., Hobbs, B., Collin, F., Beazer-Barclay, Y. D., Antonellis, K. J., Scherf, U., and Speed, T. P. 2003. Exploration, normalization, and summaries of high density oligonucleotide array probe level data Biostatistics 4:249-264.

Karimi, M., Inzé, D., and Depicker, A. 2002. GATEWAY ${ }^{\mathrm{TM}}$ vectors for Agrobacterium-mediated plant transformation. Trends Plant Sci. 7:193-195.

Kawaharada, Y., Kelly, S., Nielsen, M. W., Hjuler, C. T., Gysel, K., Muszyński, A., Carlson, R. W., Thygesen, M. B., Sandal, N., Asmussen, M. H., Vinther, M., Andersen, S. U., Krusell, L., Thirup, S., Jensen, K. J., Ronson, C. W., Blaise, M., Radutoiu, S., and Stougaard, J. 2015 Receptor-mediated exopolysaccharide perception controls bacterial infection. Nature 523:308-312. 
Koizumi, K., Sugiyama, M., and Fukuda, H. 2000. A series of novel mutants of Arabidopsis thaliana that are defective in the formation of continuous vascular network: Calling the auxin signal flow canalization hypothesis into question. Development 127:3197-3204.

Koizumi, K., Naramoto, S., Sawa, S., Yahara, N., Ueda, T., Nakano, A., Sugiyama M., and Fukuda, H. 2005. VAN3 ARF-GAP-mediated vesicle transport is involved in leaf vascular network formation. Development 132:1699-1711.

Kuusk, S., Sohlberg, J. J., Long, J. A., Fridborg, I., and Sundberg, E. 2002. STY1 and STY2 promote the formation of apical tissues during Arabidopsis gynoecium development. Development 129:4707-4717.

Kuusk, S., Sohlberg, J. J., Magnus Eklund, D., and Sundberg, E. 2006. Functionally redundant SHI family genes regulate Arabidopsis gynoecium development in a dose-dependent manner. Plant J. 47:99-111.

Laloum, T., De Mita, S., Gamas, P., Baudin, M., and Niebel, A. 2013. CCAAT-box binding transcription factors in plants: $\mathrm{Y}$ so many? Trends Plant Sci. 18:157-166.

Laloum, T., Baudin, M., Frances, L., Lepage, A., Billault-Penneteau, B., Cerri, M. R., Ariel, F., Jardinaud, M. F., Gamas, P., De Carvalho-Niebel, F., and Niebel, A. 2014. Two CCAAT-box-binding transcription factors redundantly regulate early steps of the legume-rhizobia endosymbiosis. Plant J. 79:757-768.

Laporte, P., Lepage, A., Fournier, J., Catrice, O., Moreau, S., Jardinaud, M. F., Mun, J. H., Larrainzar, E., Cook, D. R., Gamas, P., and Niebel, A. 2014. The CCAAT box-binding transcription factor NF-YA1 controls rhizobial infection. J. Exp. Bot. 65:481-494.

Leek, J. T., Monsen, E., Dabney, A. R., and Storey, J. D. 2006. EDGE: Extraction and analysis of differential gene expression. Bioinformatics 22:507-508.

Lerouge, P., Roche, P., Faucher, C., Maillet, F., Truchet, G., Promé, J. C., and Dénarié, J. 1990. Symbiotic host-specificity of Rhizobium meliloti is determined by a sulphated and acylated glucosamine oligosaccharide signal. Nature 344:781-784.

Lévy, J., Bres, C., Geurts, R., Chalhoub, B., Kulikova, O., Duc, G., Journet, E. P., Ané, J. M., Lauber, E., Bisseling, T., Dénarié, J., Rosenberg, C., and Debellé, F. 2004. A putative $\mathrm{Ca}^{2+}$ and calmodulin-dependent protein kinase required for bacterial and fungal symbioses. Science 303:1361-1364.

Li, C., and Wong, W. H. 2001. Model-based analysis of oligonucleotide arrays: Expression index computation and outlier detection. Proc. Natl. Acad. Sci. USA 98:31-36.

Limpens, E., and Bisseling, T. 2014. CYCLOPS: A new vision on Rhizobiuminduced nodule organogenesis. Cell Host Microbe 15:127-129.

Limpens, E., Franken, C., Smit, P., Willemse, J., Bisseling, T., and Geurts, R. 2003. LysM domain receptor kinases regulating rhizobial Nod factorinduced infection. Science 302:630-633.

Lombari, P., Ercolano, E., El Alaoui, H., and Chiurazzi, M. 2005. Agrobacterium-mediated in vitro transformation. Pages 251-259 in: Lotus japonicus Handbook, Springer, Dordrecht, The Netherlands.

Ly, L. L., Yoshida, H., and Yamaguchi, M. 2013. Nuclear transcription factor Y and its roles in cellular processes related to human disease. Am. J. Cancer Res. 3:339-346.

Madsen, E. B., Madsen, L. H., Radutoiu, S., Olbryt, M., Rakwalska, M., Szczyglowski, K., Sato, S., Kaneko, T., Tabata, S., Sandal, N., and Stougaard, J. 2003. A receptor kinase gene of the LysM type is involved in legume perception of rhizobial signals. Nature 425:637-640.

Madsen, L. H., Tirichine, L., Jurkiewicz, A., Sullivan, J. T., Heckmann, A. B., Bek, A. S., Ronson, C. W., James, E. K., and Stougaard, J. 2010. The molecular network governing nodule organogenesis and infection in the model legume Lotus japonicus. Nat. Commun. 1:10.

Maekawa, T., Kusakabe, M., Shimoda, Y., Sato, S., Tabata, S., Murooka, Y., and Hayashi, M. 2008. Polyubiquitin promoter-based binary vectors for overexpression and gene silencing in Lotus japonicus. Mol. PlantMicrobe Interact. 21:375-382.

Małolepszy, A., Mun, T., Sandal, N., Gupta, V., Dubin, M., Urbański, D., Shah, N., Bachmann, A., Fukai, E., Hirakawa, H., Tabata, S., Nadzieja, M., Markmann, K., Su, J., Umehara, Y., Soyano, T., Miyahara, A., Sato, S., Hayashi, M., Stougaard, J., and Andersen, S. U. 2016. The LORE1 insertion mutant resource. Plant J. 88:306-317.

Mantovani, R. 1999. The molecular biology of the CCAAT-binding factor NF-Y. Gene 239:15-27.

Marsh, J. F., Rakocevic, A., Mitra, R. M., Brocard, L., Sun, J., Eschstruth A., Long, S. R., Schultze, M., Ratet, P., and Oldroyd, G. E. D. 2007. Medicago truncatula NIN is essential for rhizobial-independent nodule organogenesis induced by autoactive calcium/calmodulin-dependent protein kinase. Plant Physiol. 144:324-335.

Mathesius, U. 2008. Auxin: At the root of nodule development? Funct. Plant Biol. 35:651-668.

Mathesius, U., Charon, C., Rolfe, B. G., Kondorosi, A., and Crespi, M. 2000. Temporal and spatial order of events during the induction of cortical cell divisions in white clover by Rhizobium leguminosarum bv. trifolii inoculation or localized cytokinin addition. Mol. Plant-Microbe Interact. 13:617-628.

Miri, M., Janakirama, P., Held, M., Ross, L., and Szczyglowski, K. 2016. Into the root: How cytokinin controls rhizobial infection. Trends Plant Sci. 21:178-186.

Mitra, R. M., Gleason, C. A., Edwards, A., Hadfield, J., Downie, J. A., Oldroyd, G. E. D., and Long, S. R. 2004. A Ca ${ }^{2+} /$ calmodulin-dependent protein kinase required for symbiotic nodule development: Gene identification by transcript-based cloning. Proc. Natl. Acad. Sci. U.S.A. 101:4701-4705.

Moreau, S., Verdenaud, M., Ott, T., Letort, S., de Billy, F., Niebel, A., Gouzy, J., de Carvalho-Niebel, F., and Gamas, P. 2011. Transcription reprogramming during root nodule development in Medicago truncatula. PLoS One 6:e16463.

Morieri, G., Martinez, E. A., Jarynowski, A., Driguez, H., Morris, R., Oldroyd, G. E. D., and Downie, J. A. 2013. Host-specific Nod-factors associated with Medicago truncatula nodule infection differentially induce calcium influx and calcium spiking in root hairs. New Phytol. 200:656-662.

Murray, J., Karas, B., Ross, L., Brachmann, A., Wagg, C., Geil, R., Perry, J., Nowakowski, K., MacGillivary, M., Held, M., Stougaard, J., Peterson, L., Parniske, M., and Szczyglowski, K. 2006. Genetic suppressors of the Lotus japonicus har 1-1 hypernodulation phenotype. Mol. Plant-Microbe Interact. 19:1082-1091.

Murray, J. D., Karas, B. J., Sato, S., Tabata, S., Amyot, L., and Szczyglowski, K. 2007. A cytokinin perception mutant colonized by Rhizobium in the absence of nodule organogenesis. Science 315:101-104

Naramoto, S., Sawa, S., Koizumi, K., Uemura, T., Ueda, T., Friml, J., Nakano, A., and Fukuda, H. 2009. Phosphoinositide-dependent regulation of VAN3 ARF-GAP localization and activity essential for vascular tissue continuity in plants. Development 136:1529-1538.

Oldroyd, G. E., and Downie, J. A. 2006. Nuclear calcium changes at the core of symbiosis signalling. Curr. Opin. Plant Biol. 9:351-357.

Oldroyd, G. E. D., Murray, J. D., Poole, P. S., and Downie, J. A. 2011. The rules of engagement in the legume-rhizobial symbiosis. Ann. Rev. Genet 45:119-144.

Parniske, M. 2008. Arbuscular mycorrhiza: The mother of plant root endosymbioses. Nat. Rev. Microbiol. 6:763-775

Petroni, K., Kumimoto, R. W., Gnesutta, N., Calvenzani, V., Fornari, M., Tonelli, C., Holt, B. F., Jr., and Mantovani, R. 2013. The promiscuous life of plant NUCLEAR FACTOR Y transcription factors. Plant Cell 24:4777-4792.

Plet, J., Wasson, A., Ariel, F., Le Signor, C., Baker, D., Mathesius, U., Crespi, M., and Frugier, F. 2011. MtCRE1-dependent cytokinin signaling integrates bacterial and plant cues to coordinate symbiotic nodule organogenesis in Medicago truncatula. Plant J. 65:622-633.

Radutoiu, S., Madsen, L. H., Madsen, E. B., Felle, H. H., Umehara, Y, Grønlund, M., Sato, S., Nakamura, Y., Tabata, S., Sandal, N., and Stougaard, J. 2003. Plant recognition of symbiotic bacteria requires two LysM receptor-like kinases. Nature 425:585-592.

Radutoiu, S., Madsen, L. H., Madsen, E. B., Jurkiewicz, A., Fukai, E., Quistgaard, E. M. H., Albrektsen, A. S., James, E. K., Thirup, S., and Stougaard, J. 2007. LysM domains mediate lipochitin-oligosaccharide recognition and $N f r$ genes extend the symbiotic host range. EMBO J. 26 3923-3935

Schaarschmidt, S., Gresshoff, P. M., and Hause, B. 2013. Analyzing the soybean transcriptome during autoregulation of mycorrhization identifies the transcription factors $\mathrm{GmNF}-\mathrm{YA} 1 \mathrm{a} / \mathrm{b}$ as positive regulators of arbuscular mycorrhization. Genome Biol. 14:R62.

Schauser, L., Roussis, A., Stiller, J., and Stougaard, J. 1999. A plant regulator controlling development of symbiotic root nodules. Nature 402:191-195

Siefers, N., Dang, K. K., Kumimoto, R. W., Bynum Iv, W. E., Tayrose, G. and Holt Iii, B. F. 2009. Tissue-specific expression patterns of Arabidopsis NF-Y transcription factors suggest potential for extensive combinatorial complexity. Plant Physiol. 149:625-641.

Singh, S., Katzer, K., Lambert, J., Cerri, M., and Parniske, M. 2014 CYCLOPS, A DNA-binding transcriptional activator, orchestrates symbiotic root nodule development. Cell Host Microbe 15:139-152.

Smith, D. L., and Fedoroff, N. V. 1995. LRP1, a gene expressed in lateral and adventitious root primordia of Arabidopsis. Plant Cell 7:735-745.

Smith, Z. D., Sindhu, C., and Meissner, A. 2016. Molecular features of cellular reprogramming and development. Nat. Rev. Mol. Cell Biol. 17: 139-154.

Sohlberg, J. J., Myrenås, M., Kuusk, S., Lagercrantz, U., Kowalczyk, M., Sandberg, G., and Sundberg, E. 2006. STY1 regulates auxin homeostasis and affects apical-basal patterning of the Arabidopsis gynoecium. Plant J. 47:112-123.

Soyano, T., and Hayashi, M. 2014. Transcriptional networks leading to symbiotic nodule organogenesis. Curr. Opin. Plant Biol. 20:146-154. 
Soyano, T., Kouchi, H., Hirota, A., and Hayashi, M. 2013. NODULE INCEPTION directly targets $N F-Y$ subunit genes to regulate essential processes of root nodule development in Lotus japonicus. PLoS Genet. 9:e1003352.

Ståldal, V., Cierlik, I., Landberg, K., Myrenås, M., Sundström, J. F., Eklund, D. M., Chen, S., Baylis, T., Ljung, K., and Sundberg, E. 2012. The Arabidopsis thaliana transcriptional activator STYLISH1 regulates genes affecting stamen development, cell expansion and timing of flowering. Plant Mol. Biol. 78:545-559.

Suzaki, T., Yano, K., Ito, M., Umehara, Y., Suganuma, N., and Kawaguchi, M. 2012. Positive and negative regulation of cortical cell division during root nodule development in Lotus japonicus is accompanied by auxin response. Development 139:3997-4006.

Suzaki, T., Yoro, E., and Kawaguchi, M. 2015. Leguminous plants: Inventors of root nodules to accommodate symbiotic bacteria. Int. Rev. Cell Mol. Biol. 316:111-158.

Takanashi, K., Sugiyama, A., and Yazaki, K. 2011. Involvement of auxin distribution in root nodule development of Lotus japonicus. Planta 234: 73-81.

Tirichine, L., James, E. K., Sandal, N., and Stougaard, J. 2006a. Spontaneous root-nodule formation in the model legume Lotus japonicus: A novel class of mutants nodulates in the absence of rhizobia. Mol. PlantMicrobe Interact. 19:373-382.

Tirichine, L., Imaizumi-Anraku, H., Yoshida, S., Murakami, Y., Madsen, L. H., Miwa, H., Nakagawa, T., Sandal, N., Albrektsen, A. S., Kawaguchi, M., Downie, A., Sato, S., Tabata, S., Kouchi, H., Parniske, M., Kawasaki, S., and Stougaard, J. 2006b. Deregulation of a $\mathrm{Ca}^{2+} /$ calmodulin-dependent kinase leads to spontaneous nodule development. Nature 441:1153-1156.

Tirichine, L., Sandal, N., Madsen, L. H., Radutoiu, S., Albrektsen, A. S., Sato, S., Asamizu, E., Tabata, S., and Stougaard, J. 2007. A gain-offunction mutation in a cytokinin receptor triggers spontaneous root nodule organogenesis. Science 315:104-107.

Urbański, D. F., Małolepszy, A., Stougaard, J., and Andersen, S. U. 2012. Genome-wide LORE1 retrotransposon mutagenesis and highthroughput insertion detection in Lotus japonicus. Plant J. 69: 731-741.

Verdier, J., Torres-Jerez, I., Wang, M., Andriankaja, A., Allen, S. N., He, J., Tang, Y., Murray, J. D., and Udvardi, M. K. 2013. Establishment of the Lotus japonicus gene expression atlas (LjGEA) and its use to explore legume seed maturation. Plant J. 74:351-362.

Vernié, T., Kim, J., Frances, L., Ding, Y., Sun, J., Guan, D., Niebel, A., Gifford, M. L., de Carvalho-Niebel, F., and Oldroyd, G. E. D. 2015. The NIN transcription factor coordinates diverse nodulation programs in different tissues of the Medicago truncatula root. Plant Cell 27:3410-3424.

Wopereis, J., Pajuelo, E., Dazzo, F. B., Jiang, Q., Gresshoff, P. M., De Bruijn, F. J., Stougaard, J., and Szczyglowski, K. 2000. Short root mutant of Lotus japonicus with a dramatically altered symbiotic phenotype. Plant J. 23:97-114.

Xiao, T. T., Schilderink, S., Moling, S., Deinum, E. E., Kondorosi, E., Franssen, H., Kulikova, O., Niebel, A., and Bisseling, T. 2014. Fate map of Medicago truncatula root nodules. Development 141:3517-3528.

Yano, K., Yoshida, S., Müller, J., Singh, S., Banba, M., Vickers, K., Markmann, K., White, C., Schuller, B., Sato, S., Asamizu, E., Tabata, S. Murooka, Y., Perry, J., Wang, T. L., Kawaguchi, M., Imaizumi-Anraku, H., Hayashi, M., and Parniske, M. 2008. CYCLOPS, a mediator of symbiotic intracellular accommodation. Proc. Natl. Acad. Sci. U.S.A. 105:20540-20545.

Yoro, E., Suzaki, T., Toyokura, K., Miyazawa, H., Fukaki, H., and Kawaguchi, M. 2014. A positive regulator of nodule organogenesis, NODULE INCEPTION, acts as a negative regulator of rhizobial infection in Lotus japonicus. Plant Physiol. 165:747-758.

Zanetti, M. E., Blanco, F. A., Beker, M. P., Battaglia, M., and Aguilar, O. M. 2010. A C subunit of the plant nuclear factor NF-Y required for rhizobial infection and nodule development affects partner selection in the common bean-Rhizobium etli symbiosis. Plant Cell 22:41424157.

Zhao, Y. 2012. Auxin biosynthesis: A simple two-step pathway converts tryptophan to indole-3-acetic acid in plants. Mol. Plant 5:334-338.

\section{AUTHOR-RECOMMENDED INTERNET RESOURCES}

ArrayExpress database: https://www.ebi.ac.uk/arrayexpress

Centre for Carbohydrate Recognition and Signalling Lotus janponicus retrotransposon resource: http://users-mb.au.dk/pmgrp

University of Ghent Gateway vector website:

https://gateway.psb.ugent.be/search

Kazusa Research Institute's L. japonicus genome clone list: http://www.kazusa.or.jp/lotus/clonelist.html

Kazusa Research Institute's Lotus japonicus database: http://www.kazusa.or.jp/lotus/index.html

L. japonicus LORE1 retrotransposon mutant resource: https://lotus.au.dk

The Noble Foundation's Lotus japonicus gene expression atlas database: http://ljgea.noble.org/v2 